\title{
EL ENFOQUE ECONÓMICO DEL DERECHO DE DAÑOS *
}

\author{
Diego M. Papayannis ** \\ Universidad de Girona
}

RESUMEN. El objeto de este trabajo es presentar una serie de objeciones en contra de las tesis explicativas del análisis económico del Derecho de daños. Ellas toman como eje central la distorsión conceptual que se produce cuando se interpreta la responsabilidad extracontractual a la luz del principio de eficiencia. En particular, se argumenta que el uso exclusivo del balance entre costos y beneficios no permite dar cuenta de la práctica efectiva de los tribunales. El razonamiento consecuencialista no se ajusta a la argumentación que lleva a un juicio de responsabilidad - fuertemente marcado por un lenguaje deóntico- ni al sentido de las decisiones judiciales. Así, entre otras cosas, la eficiencia es incapaz de sostener la diferencia conceptual que existe entre la conducta incorrecta y la conducta meramente riesgosa; tampoco puede capturar la relevancia de la causalidad en el Derecho de daños, ni explicar la estructura bilateral de la responsabilidad extracontractual. Por estas razones, las teorías económicas no pueden ofrecer una imagen del Derecho de daños que sea reconocible por aquellos individuos que adoptan el punto de vista interno.

Palabras clave: Derecho de daños, análisis económico del Derecho.

ABSTRACT. The purpose of this article is to raise a number of objections to the economic explanation of tort law. They are primarily based on the conceptual distortion that occurs when tort law is interpreted in light of the efficiency principle. Particularly, it is argued that the exclusive use of the cost benefit analysis cannot provide an account of the actual practice of the Courts. The consequentialist reasoning does not fit in with the arguments leading to a responsibility judgment - that strongly stresses the deontic language - nor with the sense of the judicial decisions. So, among other things, the efficiency principle cannot account for the conceptual distinction between wrongful conduct and merely risky conduct; neither can capture the relevance of causation in tort law, nor explain its bilateral structure. For these reasons, economic theories cannot provide a representation of tort law that is recognizable for those individuals who take up the internal point of view.

Keywords: tort law, law and economics.

* Fecha de recepción: 29 de junio de 2009. Fecha de aceptación: 30 de julio de 2009.

** Universidad de Girona. Me he beneficiado mucho de los comentarios que a una versión anterior de este trabajo realizaron Í. Ortiz de Urbina, J. L. Martí, L. Morales, J. Queralt, L. Ramírez, M. Iglesias, J. Ferrer, M. Bermejo, J. M. ${ }^{a}$ Vilajosana, G. Battista Ratti, R. Calvo, E. Rivera López, M. Ferrante, M. Hevia, M. Farrell, M. Alegre, L. Grosman, C. Rosenkrantz, G. Coloma, P. Salvador Coderch, F. Gómez Pomar y C. Gómez. 


\section{INTRODUCCIÓN}

El Análisis Económico del Derecho (AED) sostiene tesis positivas y tesis normativas. A su vez, usualmente se reconocen dos clases de tesis positivas ${ }^{1}$. Hay estudios que se encargan de medir el impacto que una determinada norma o cuerpo normativo tendrá sobre la eficiencia o el bienestar social. Estas tesis son fundamentalmente predictivas. Así, ante la aprobación de nuevas leyes que hacen solidariamente responsables a todos los intervinientes en la cadena de producción, distribución y comercialización de bienes y servicios por los daños que sufren los consumidores, las preguntas que se formularía el analista en relación con estas normas podrían ser: 1) ¿en qué medida se reducirá la cantidad de accidentes?; 2) ¿cómo afectará la imposición de responsabilidad solidaria al precio final del bien o servicio?; 3) ¿cómo impactará la subida del precio, en caso de darse, sobre el acceso de los consumidores al producto en cuestión?; 4) ¿podrá el sistema de seguros dispersar el coste de estos accidentes?

Otros trabajos, en cambio, tienen una pretensión explicativa. Para POSNER, por ejemplo, las reglas del Common Law pueden ser mejor interpretadas como esfuerzos de los jueces, conscientes o no, por lograr resultados óptimos. Entonces, la maximización de la riqueza es la mejor forma — aunque no es perfecta— de comprender el sistema jurídico norteamericano y sus doctrinas ${ }^{2}$. La mayoría de las investigaciones actualmente se orientan al primer sentido de análisis positivo recién mencionado. Es decir, intentan aplicar la metodología económica para determinar los efectos de las distintas reglas jurídicas sobre la eficiencia y la distribución de los recursos. Sin embargo, la influencia de los teóricos más extremos sigue presente en el discurso jurídicoeconómico. Ello se debe a que parece haber una relación muy estrecha entre predecir y explicar. El relativo prestigio logrado en la primera tarea hace suponer a muchos partidarios del AED que cuentan con una teoría capaz de iluminar todos los aspectos de las prácticas jurídicas.

En esta línea, los trabajos sobre Derecho de daños se preocupan por ofrecer un análisis de los conceptos empleados en la práctica. Los teóricos suelen reconocer que el daño, la idea de deberes y derechos correlativos, la causalidad, la culpa y la responsabilidad objetiva, entre otros conceptos, cumplen un rol central en la teoría general de la reparación. Por ello, intentan determinar cuál es el contenido de estos conceptos y cuál es la conexión que existe entre ellos. En la medida en que pueda explicitarse un principio, o un conjunto bien articulado de principios, que conecten estos conceptos fundamentales de manera plausible, el teórico habrá ofrecido una explicación conceptual. J. COLEMAN, el autor que más ha trabajado esta cuestión, entiende que los conceptos a los que me refiero organizan la práctica del Derecho de daños y que el principio de justicia correctiva hace transparente la manera en que están relacionados y las inferencias que llevan a un juicio de responsabilidad ${ }^{3}$. Los partidarios del AED, en cambio, consideran que la eficiencia es el principio que explica con mayor precisión la estructura de la responsabilidad extracontractual. El contenido de conceptos como la

\footnotetext{
1 Vid. Ogus, 2004, pp. 384-385.

POSNER, 1998, p. 27.

Coleman, 2001, pp. XV y 13.
} 
negligencia, la causalidad o la conducta riesgosa, y la manera en que se articulan estas nociones puede comprenderse a la luz de la eficiencia. Para ello, no obstante, deben recaracterizar todo este entramado conceptual en términos económicos. Se verá más adelante que, de acuerdo con las tesis del AED, la culpa no es más que un juicio que resulta de la comparación entre el coste de las medidas precautorias y el valor esperado del daño. Se considera negligente a quien puede evitar o reducir el coste de un accidente invirtiendo en medidas precautorias una suma menor que el valor del daño multiplicado por la probabilidad de su ocurrencia y, pese a ello, no toma las medidas en cuestión. El AED no hace más que traducir todos los conceptos valiéndose de otros conceptos más fundamentales. Los conceptos de negligencia o de causalidad, que son conceptos jurídicos, pueden ser reducidos a otro concepto más fundamental (no jurídico sino económico); este concepto es la eficiencia.

Las tesis normativas, por su parte, no pretenden explicar la práctica del Derecho de daños reconstruyendo sus conceptos centrales, ni predecir los efectos económicos de las reglas vigentes, sino proponer reformas a fin de implementar políticas eficientes. La eficiencia, considera esta corriente de pensamiento, es un valor social que debe ser promovido. La maximización de la riqueza social es un imperativo ético, según las visiones más ortodoxas, ya que en un mundo de recursos escasos el derroche debe ser considerado inmoral ${ }^{4}$. Otras versiones más moderadas, como la de CALABRESI al estudiar el Derecho de daños, entienden que son varios los objetivos que compiten con la eficiencia. También hay consideraciones distributivas que son relevantes y un veto dado por la justicia al tipo de políticas que pueden desarrollarse para conseguir estos objetivos $^{5}$.

En este trabajo no me ocuparé de criticar las tesis normativas del AED. Luego del famoso debate del que participaron DwORKIN, POSNER y CALABRESI ${ }^{6}$ a principios de los ochenta, ha quedado claro que la eficiencia no puede servir como único criterio de justicia para evaluar las instituciones sociales ${ }^{7}$. Tampoco formularé objeción alguna contra los estudios que consisten en la aplicación del método económico para predecir el impacto de las reglas de responsabilidad extracontractual. Considero que este tipo de trabajos son de gran valor para conocer los efectos que produce el Derecho de daños sobre el nivel de riqueza social y su distribución.

Me centraré en las pretensiones explicativas de las tesis positivas. Intentaré mostrar que el AED es incapaz de brindar una explicación conceptual del Derecho de daños porque no logra recaracterizar las nociones fundamentales de la práctica, ni dar sentido a las inferencias que se realizan para justificar un juicio de responsabilidad.

Presentaré el argumento del siguiente modo: en las secciones II y III explicaré que una concepción agregativa de la sociedad necesariamente nos conduce a analizar el fenómeno de los daños como un problema de naturaleza recíproca. Si se interpreta que los beneficios y las pérdidas de los individuos son beneficios y pérdidas de la sociedad, entonces, no hay razón para identificar a ciertos individuos como agentes dañadores,

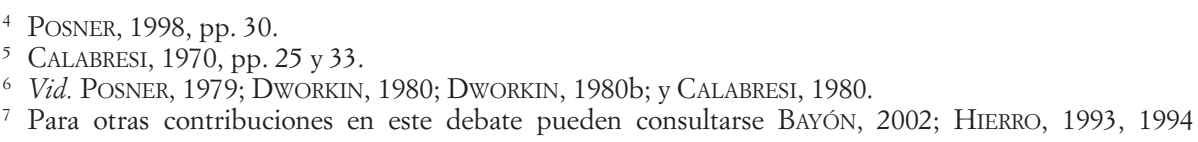


que deberán pagar una compensación, y a otros como víctimas, que tendrán derecho a ser indemnizados, antes de saber qué se gana y qué se pierde con cada esquema alternativo. Desde este punto de vista, según el AED, las políticas en materia de daños deben estar dirigidas a minimizar el coste agregado de los accidentes, el que soportan todos los individuos de la sociedad en su conjunto. Para ello, se debe instaurar un sistema de reglas de responsabilidad extracontractual basado exclusivamente en un análisis coste-beneficio. Este análisis, de acuerdo con la teoría económica positiva, subyace a todas las reglas del sistema y a todas las doctrinas creadas por los jueces y los juristas.

En la sección IV, argumentaré que este paradigma, el de la naturaleza recíproca del problema, es un paradigma equivocado para estudiar la responsabilidad civil. El análisis coste-beneficio como único criterio no resulta explicativo de la responsabilidad extracontractual por varias razones. En primer lugar, la teoría económica no puede dar cuenta de la práctica efectiva de los tribunales. No puede explicar por qué el razonamiento expresado en las sentencias tiene que ver con consideraciones distintas de la eficiencia; ni por qué los resultados de las sentencias, producto del razonamiento real de los jueces, tampoco coincide con la maximización de la riqueza social. Por supuesto, esto no implica afirmar que los sistemas de responsabilidad extracontractual operen absolutamente al margen de la eficiencia. Solo una comunidad autodestructiva gestionaría sus accidentes con un sistema normativo que la conduzca al total desperdicio de los recursos.

En segundo lugar, la teoría económica ofrece una explicación reduccionista que atribuye un significado consecuencialista a los términos deónticos que se expresan en las sentencias y ello, en última instancia, no permite comprender de modo transparente las inferencias que se realizan cuando se decide que el coste de un accidente sea trasladado de la víctima al agente dañador. Para mostrar esto, analizaré la interpretación económica de la culpa, la responsabilidad objetiva y la causalidad.

Por último, el principio de eficiencia no puede dar cuenta de un rasgo obvio para cualquiera familiarizado con nuestros sistemas de compensación de daños. Me refiero a la bilateralidad. En la mayoría de los sistemas occidentales el agente dañador está vinculado con la víctima de un modo particular. La doctrina de la causalidad imposibilita fundar la responsabilidad de un individuo que no causó de algún modo relevante el daño a la víctima. No obstante, una vez comprobada la relación causal, el agente dañador debe a la víctima, y solo a ella, el monto del daño, ni más ni menos, y la víctima tiene derecho a ser indemnizada por el agente dañador, y por nadie más. Esta vinculación que el Derecho establece luego del acaecimiento del daño en ciertas condiciones es una típica relación de Derecho privado y su principal característica es la bilateralidad. Se verá en el punto IV.4 que el AED no puede explicar esta característica relativa a la organización de la práctica. En otras palabras, no puede justificar con razones económicas que el Derecho de daños tenga una estructura bilateral.

Uno podría preguntarse, de todas maneras, si es importante que el AED pueda dar cuenta del esquema conceptual que se emplea en la práctica. Es más, un partidario del análisis económico podría responder sosteniendo que justamente pretende cuestionar que estas categorías sean explicativas y por este motivo no puede dar cuenta de ellas. Podría afirmar que los juicios de responsabilidad son puros juicios de eficiencia, y que el discurso práctico desarrollado en la práctica para justificar las decisiones no es más 
que un manto de opacidad que esconde las verdaderas funciones del Derecho de daños. En el punto $V$ me ocuparé de responder a esta objeción. Veamos primero en qué consiste la explicación económica y cuáles son sus problemas conceptuales.

\section{LA NATURALEZA RECÍPROCA DEL PROBLEMA Y LOS OBJETIVOS DEL DERECHO DE DAÑOS}

The Problem of Social Cost ${ }^{8}$ supuso una ruptura con la forma en la que tradicionalmente los juristas y los economistas analizaban el fenómeno de los daños. Según la visión tradicional, expuesta por PIGOU ${ }^{9}$, los daños son una externalidad negativa que debe ser corregida mediante la intervención estatal. Las externalidades son efectos, positivos o negativos, que la producción o el consumo de un bien generan sobre la producción o el consumo de otros bienes. Típicamente en los casos de efectos externos hay una divergencia entre el coste privado y el coste social de la actividad ${ }^{10}$. A raíz de esto, las cantidades consumidas o producidas del bien que origina la externalidad negativa son mayores que las eficientes.

¿Cómo puede lograrse que el agente detenga su actividad en el nivel socialmente deseable? PIGOU creía que la clave estaba en hacer que internalice el coste total. Esto se logra obligándole a pagar un impuesto que equipare su coste marginal privado con el coste marginal social o haciéndolo responsable por los daños que sufren los terceros. El monto indemnizatorio (o del impuesto) debería ser igual a la diferencia entre el coste marginal social y el coste marginal privado.

Lo novedoso del enfoque de COASE está en acercarse al mundo de los daños profundizando la visión agregativa de la sociedad. Desde este punto de vista lo relevante es la suma total de excedentes, por lo que las pérdidas de algunos no son decisivas al evaluar un estado social si son superadas por las ganancias obtenidas por otros. La profundización de esta visión agregativa llevó a COASE a sostener que el problema de los daños es de naturaleza recíproca. Cuando dos actividades son rivales, en el sentido de que no pueden realizarse a la vez, la teoría tradicional intenta establecer una relación causal entre una acción y un resultado dañoso para luego reprimir la acción dañadora. Sin embargo, según COASE esto es un error ya que, en estos casos, «evitar el daño a B implica causar daño a A. Lo que realmente corresponde resolver es: ¿debe permitirse que $A$ perjudique a $B$ o debe permitirse que $B$ perjudique a $A$ ? El problema es evitar el daño más grave» ${ }^{11}$.

Supongamos que un carpintero, que obtiene 100 de beneficio por su actividad, realiza sus tareas junto a un médico que por su consulta recibe solo 50 de beneficio. Imaginemos que el ruido de la carpintería impide al médico atender a sus pacientes y

8 COASE, 1960.

9 CoAse toma como referencia el análisis de PigOU, 1932.

10 El coste privado de la actividad es el que asume el agente que emprende un determinado curso de acción. El coste social, incluye no solo el coste del agente sino el que soportan los terceros. Así, si Jordi desarrolla una actividad cuya realización implica un coste de diez, pero impone a Oriol un coste de cinco en daños, el coste social de la actividad será de quince.

11 CoAse, 1960, p. 2. 
que no hay medidas precautorias que puedan adoptarse para disminuir el ruido. En este contexto, la visión tradicional identificaría al carpintero como agente dañador y lo obligaría a compensar al médico. No obstante, COASE observa que la intervención estatal no es necesaria para una asignación eficiente de los recursos si los derechos de las partes están bien definidos y no hay costes de transacción, por lo que ellas pueden negociar libremente. Esto es lo que se conoce como el Teorema de COASE. En teoría, si el sistema jurídico reconoce al carpintero un derecho a hacer ruido, en esa sociedad habrá carpintería y el resultado será eficiente. Del mismo modo, si el sistema reconociese al médico un derecho al silencio, el resultado será idéntico, ya que el carpintero estará gustoso de pagar al médico una suma entre 50 y 100 para que abandone su consulta y le permita hacer ruido. En conclusión, la asignación de recursos será la misma, independientemente de quién tenga el derecho de propiedad. La libre negociación entre las partes resolverá la situación de manera óptima. A quien se otorgue el derecho de propiedad no es indiferente, sin embargo, para definir la riqueza de las partes ${ }^{12}$. Otorgar al médico un derecho al silencio hace automáticamente más pobre al carpintero. Inversamente, otorgar a este último el derecho a hacer ruido hace más pobre al médico. Pero esta es una cuestión de política distributiva que al economista no debe preocupar.

No obstante, en general, el contexto de los accidentes es un contexto en el que la negociación entre las partes no es posible. Se trata de contextos en los que los agentes dañadores y las víctimas no se conocen o no pueden determinar ex ante el valor del daño, por tanto, no pueden negociar. Así las cosas, los sistemas de responsabilidad civil protegen los derechos con reglas de responsabilidad y no con reglas de propiedad. Según una vieja clasificación de CALABRESI y MELAMED, un derecho está protegido por una regla de propiedad cuando se requiere a quien desee adquirirlo que lo haga de su actual propietario por medio de una transacción voluntaria. El precio del derecho se acuerda libremente entre ambas partes. Las reglas de propiedad implican un juicio sobre a quién debe otorgarse el derecho pero no sobre su valor. En cambio, un derecho está protegido por una regla de responsabilidad cuando puede ser destruido siempre que se esté dispuesto a pagar un valor objetivo determinado colectivamente ${ }^{13}$. El fundamento de las reglas de responsabilidad civil es facilitar tantas transferencias no voluntarias de derechos como sean necesarias para lograr una asignación de recursos óptima. Cuando esta asignación es eficiente se habrá logrado el objetivo de minimizar el coste de los accidentes.

A esta altura ya puede apreciarse que comprender el fenómeno de los daños como un problema de naturaleza recíproca implica adoptar una visión agregativa del mundo, en la que las pérdidas y las ganancias del carpintero y del médico son interpretadas como pérdidas y ganancias de la sociedad. Si un mismo empresario fuese dueño de la carpintería y del consultorio médico indudablemente optaría por hacer funcionar la carpintería, ya que el beneficio que obtendría es mayor que si hace funcionar el consultorio ${ }^{14}$. Lo que demuestra el Teorema de Coase es que cuando los costes de

12 COASE, 1960 , p. 5

13 Calabresi y Melamed, 1972, p. 1092.

14 Cuando funciona la carpintería la sociedad obtiene un beneficio de 100 menos 50 que pierde el médico. Cuando funciona el consultorio la sociedad se empobrece porque obtiene 50 de beneficio menos 
transacción son bajos la libre negociación entre las partes conducirá a este mismo resultado eficiente. Pero cuando son positivos, debe asignarse el derecho al que realiza la actividad más valiosa.

Esta filosofía se traslada a la interpretación del Derecho de daños. Así, por ejemplo, al analizar la regla de la culpa se suele citar la famosa fórmula que el juez Learned Hand expresó en el caso United States v. Carroll Towing Co (159 F. 2d 169). Allí sostuvo que el agente dañador es negligente cuando el coste de las medidas precautorias es menor que el valor del accidente multiplicado por la probabilidad de su ocurrencia y pese a ello haya omitido el comportamiento diligente ${ }^{15}$. La razón por la que se considera negligente únicamente a aquél que no adopta medidas cuando se da esta condición es que a un coste mayor que el valor esperado del daño no tiene sentido invertir en diligencia (sería absurdo invertir 60 para evitar un daño de 50). Para el AED el coste de un accidente comprende el valor esperado del daño, el coste de las medidas precautorias necesarias para evitarlo o disminuir su probabilidad de ocurrencia y el coste de administrar el sistema de responsabilidad civil ${ }^{16}$. Nuevamente, la visión agregativa hace que deban considerarse los beneficios y los costes asumidos por distintos individuos como beneficios y perjuicios de la sociedad.

A esta concepción agregativa de la sociedad el AED suma una concepción instrumentalista del Derecho ${ }^{17}$. En particular, el Derecho de daños como un cuerpo normativo orientado a la satisfacción de objetivos concretos. CALABRESI, en su clásico libro The Costs of Accidents, postula que el objetivo del Derecho de daños es reducir el coste de los accidentes, y para alcanzarlo se requiere una teoría que permita diseñar el sistema con esa finalidad. En este sentido, lo primero que CALABRESI advierte es que la visión relacional o bilateral del Derecho de daños — que implica vincular muy especialmente al agente dañador con la víctima del accidente- no es más que un gran mito que debe ser abandonado por los juristas. Sostiene expresamente que «no hay una relación necesaria entre el criterio para asignar compensación y el criterio para asignar los costes de la compensación». Más adelante refuerza la idea al afirmar que «no existe virtualmente límite alguno en la manera en la que podemos asignar o distribuir el coste de los accidentes» ${ }^{18}$. Esto implica desintegrar la idea de agente dañador y víctima, lo que resulta perfectamente coherente con el análisis de COASE.

Ahora bien, si el problema es de naturaleza recíproca y los beneficios y los perjuicios no deben ser interpretados como sufridos por los individuos sino por la so-

\footnotetext{
100 que deja de ganar la carpintería. Como dije, un empresario que fuese propietario de ambos establecimientos haría funcionar la carpintería. Para el AED, las normas jurídicas deberían promover este mismo resultado.

15 En realidad, según la interpretación usual de la fórmula de HAND, la relación entre la precaución y el valor esperado del accidente debe medirse en términos marginales. Siendo ello así, será negligente el agente que no adopte medidas precautorias cuyo beneficio marginal sea superior a su coste marginal. El beneficio marginal está dado por la reducción en el valor del daño respecto del nivel de precaución anterior. Sobre las distintas interpretaciones de la fórmula de HAND puede consultarse BROwN, 1973, pp. 332-335.

16 CALABRESI, 1970, pp. 26-28. Así, en una sociedad en la que Juan ha sufrido un daño de 1.000, Lucas un daño de 2.000, Mateo un daño de 500, Marcos ha invertido 50 en medidas precautorias para disminuir la probabilidad de ser dañado y el coste de reclamar por daños es de 300, el coste monetario del accidente asciende a 3.850 .

${ }_{17}$ Para una exposición de la concepción instrumentalista, vid., entre otros, RAz, 1996, p. 7.

18 CAlabresi, 1970, p. 23.
} 
ciedad ¿qué sentido tiene la compensación del daño? ¿Qué objetivos satisfacen la obligación de compensar y el derecho a ser indemnizado desde un punto de vista agregativo?

Las razones por las que se exige compensación son varias y tienen que ver con los incentivos que reciben tanto el agente dañador como la víctima. Una explicación sencilla y breve que ofrecen los partidarios del AED es que la responsabilidad del agente se justifica a fin de brindarle los incentivos necesarios para que adopte un comportamiento eficiente, ya sea tomando medidas precautorias o limitando su nivel de actividad. Sin responsabilidad, no tendría motivación alguna para prevenir daños. Por parte de la víctima hay dos razones por las cuales debe recibir compensación por los daños que sufre. En primer lugar, debe brindársele un incentivo para que demande judicialmente. Esto resulta esencial para mantener un sistema de responsabilidad civil efectivo a nivel disuasorio. Además, es importante que la víctima sea compensada para evitar que adopte medidas precautorias excesivas. Si no existiese compensación habría una tendencia de las potenciales víctimas a invertir demasiados recursos en autoprotección ${ }^{19}$.

Veamos ahora cómo contribuyen las reglas de responsabilidad en la consecución de los objetivos generales del sistema de reparación de daños.

\section{LAS REGLAS DE RESPONSABILIDAD}

Una vez determinados los objetivos del Derecho de daños, las reglas de responsabilidad son evaluadas por los incentivos que generan sobre la conducta de las partes involucradas en el accidente, y por el coste de administrar el sistema de reparación ${ }^{20}$. No obstante, aquí me ocuparé únicamente de los incentivos que reciben las partes. Hay casos en los que el agente dañador es el único que puede adoptar medidas precautorias para evitar o reducir la probabilidad de que ocurra el accidente. Estos casos son denominados de precaución unilateral, lo que implica que el nivel de precaución eficiente de la víctima es cero. Cuando la víctima también puede adoptar medidas precautorias a coste razonable, y por ello se requiere que lo haga, el caso será de precaución bilateral. Por otra parte, el nivel de actividad de los agentes también influye sobre la cantidad de accidentes. Es evidente que quien conduce todos los días, aunque sea diligentemente, incrementa la probabilidad de causar un accidente respecto de aquel que sólo conduce una vez a la semana. En ocasiones, es importante que el individuo adopte medidas precautorias y también que limite su nivel de actividad. Entonces, éstos serán dos aspectos

19 Posner, 1998, p. 209.

20 Shavell, 1987, p. 262. Los costes de administración dependen de la cantidad de demandas y del coste de pronunciar una sentencia en cada una de ellas. Así, la regla de responsabilidad objetiva eleva el número de reclamos, ya que en principio todo agente que haya causado el daño es responsable y las posibilidades de éxito son altas. Una regla de responsabilidad por culpa, por su parte, incentiva a demandar en menor medida que una regla de responsabilidad objetiva porque sólo se recibirá indemnización si el agente dañador obró con culpa. En cuanto al coste de decidir el litigio, la regla de responsabilidad por culpa entraña un coste más alto que la regla de responsabilidad objetiva, simplemente por el esfuerzo probatorio que debe realizarse en uno y otro caso. Para lograr compensación con la primera regla debe probarse el daño, la relación de causalidad y la culpa del agente dañador. En cambio, con la segunda regla basta probar el daño y la relación de causalidad. 
relevantes para valorar el impacto de las reglas de responsabilidad civil. A los fines de este trabajo no es necesario analizar los casos de precaución bilateral ${ }^{21}$.

Antes que nada debe recordarse que las medidas precautorias óptimas, definidas a partir de la fórmula de HAND, por definición minimizan el coste del accidente ${ }^{22}$. Esto significa que cuando se adoptan las medidas precautorias óptimas, el valor esperado del daño sumado al coste de las medidas es el mínimo que puede lograrse. En otras palabras, siendo el coste esperado del accidente $(C e)$ igual a la suma del daño $(D)$ ponderado por la probabilidad de su ocurrencia $(p)$ y el coste de las medidas precautorias $(A)$, que dependen del nivel de diligencia $(y)$, las medidas óptimas $\left(y^{*}\right)$ son las que minimizan $C e^{23}$. En el modelo que presento aquí presupongo que el estándar jurídico de diligencia, establecido por el legislador y los jueces, coincide perfectamente con el estándar eficiente.

En lo que hace a los casos de precaución unilateral, tanto la regla de negligencia como la de responsabilidad objetiva producen los mismos efectos: el agente dañador obrará con la diligencia debida. Ello es así porque bajo el régimen de negligencia si no adopta medidas eficientes deberá cargar con el valor del daño, y ya sabemos por definición que el valor de daño es mayor que el valor de las medidas eficientes $[D \cdot p(y)>A$ $\left(y^{*}\right)$. De igual manera, bajo el régimen de responsabilidad objetiva deberá cargar con el coste esperado del accidente más allá de su diligencia, sin embargo, para minimizar este valor también adoptará el nivel de precaución eficiente [recuérdese que $D \cdot p(y)+$ $\left.A(y)>D \cdot p\left(y^{*}\right)+A\left(y^{*}\right)\right]$.

Ahora bien, hasta aquí puede afirmarse que ambas reglas incentivan correctamente al agente dañador para que adopte un nivel de precaución eficiente. Pero ¿qué ocurre con el nivel de actividad? A continuación completaré el modelo para determinar esta cuestión presuponiendo dos cosas: a) que un aumento en el nivel de actividad eleva el coste esperado de los daños, y $b$ ) que un aumento en el nivel de actividad incrementa, al menos hasta cierto punto, la utilidad del agente ${ }^{24}$.

Supongamos que Jordi realiza una actividad capaz de producir un daño de 50 cuando no toma medidas precautorias, pero la probabilidad de su ocurrencia disminuye en un 50 por 100 si invierte diez en la diligencia óptima. El beneficio que obtiene de la actividad es de 100. Imaginemos también que Jordi tiene la posibilidad de reducir su nivel de actividad, obteniendo un beneficio de sólo 80 , lo que disminuye la probabilidad de que ocurra un accidente al 20 por 100, de modo que el coste esperado del daño es diez y lo óptimo es que no invierta en medidas precautorias de ningún tipo ${ }^{25}$. Resumida en un cuadro, la situación es la siguiente:

${ }^{21}$ Para un análisis completo de las reglas de responsabilidad civil pueden consultarse SHAVELL, 1987, capítulo 2; y LANDES y POSNER, 1987, capítulos 3 y 4.

22 El nivel de precaución eficiente se caracteriza por ser aquél en el cual el beneficio marginal del incremento de precaución se iguala con el costo marginal que dicho incremento acarrea. Vid. CoLOMA, 2001, p. 151.

${ }^{23}$ Dado que $C e=D \cdot p(y)+A(y), y^{*}$ es el valor que minimiza $C e$. Entonces, cuando $y \neq y^{*}$ por definición se dará que $D \cdot p(y)+A(y)>D \cdot p\left(y^{*}\right)+A\left(y^{*}\right)$, o lo que es lo mismo, $C e(y)>C e\left(y^{*}\right)$.

24 ShavelL, 1987, p. 21.

${ }^{25}$ El nivel óptimo de precaución puede depender, como en este ejemplo, del nivel de actividad. Por ello, con la actividad inicial puede ser óptimo invertir diez en diligencia, pero si se reduce la actividad puede ser óptima una precaución menor, o incluso ninguna. Un ejemplo sencillo ilustrará este punto. Un individuo puede 


\begin{tabular}{|l|c|c|c|c|c|c|}
\hline \multicolumn{1}{|c|}{$\begin{array}{c}\text { Nivel } \\
\text { de actividad }\end{array}$} & $\begin{array}{c}\text { Beneficio } \\
\text { para el } \\
\text { agente } \\
\text { dañador }\end{array}$ & $\begin{array}{c}\text { Medidas } \\
\text { precauto- } \\
\text { rias ópti- } \\
\text { mas }\end{array}$ & Daño & $\begin{array}{c}\text { Probabi- } \\
\text { lidad de } \\
\text { ocurrencia }\end{array}$ & $\begin{array}{c}\text { Coste } \\
\text { esperado } \\
\text { del daño }\end{array}$ & $\begin{array}{c}\text { Excedente } \\
\text { social }\end{array}$ \\
\hline Nivel inicial & 100 & 10 & 50 & $50 \%$ & 25 & 65 \\
\hline Nivel reducido & 80 & 0 & 50 & $20 \%$ & 10 & 70 \\
\hline
\end{tabular}

La riqueza social se maximiza cuando el agente dañador reduce su actividad. Nótese que con la actividad inicial el beneficio social es de $65(100-10-25)$ mientras que con la actividad limitada es de $70(80-10-0)$. Esto significa que a la sociedad en su conjunto le resulta conveniente que se restrinja el nivel de actividad. Un régimen de responsabilidad objetiva, a diferencia de la regla de negligencia, logrará el objetivo de minimizar el coste del accidente. Veamos por qué. En todos los casos, el agente dañador tomará su decisión respecto del nivel de actividad en base al excedente que obtiene cuando realiza la actividad a su nivel inicial y el que obtiene cuando la reduce. Este excedente depende del tipo de regla de responsabilidad que regule su conducta. Cuando la regla es de negligencia, invirtiendo diez en medidas precautorias se libera de responsabilidad, entonces comparará los beneficios que obtiene de la actividad al nivel inicial ( $\left.\mathrm{B}^{\mathrm{i}}\right)$ con los que obtiene de la actividad reducida $\left(B^{r}\right)$, descontando en ambos casos los costes de las medidas precautorias óptimas para cada nivel. Así, elegirá el nivel según $B^{i}-A\left(x^{i *}\right)>0<B^{r}-A\left(x^{r * *}\right)$. Como en el caso de la tabla el nivel inicial le reporta un excedente de 90 y la reducción uno de 80 , el resultado será ineficiente.

Con una regla de responsabilidad objetiva el cálculo es distinto. Su decisión de reducir el nivel de actividad dependerá de que $B^{i}-D \cdot p\left(x^{i *}\right)-A\left(x^{i *}\right)>0<B^{r}-D \cdot p\left(x^{r * *}\right)$ - $A\left(x^{r * *}\right)$. En el ejemplo de la tabla como el nivel inicial le supone un excedente de 65 $(100-25-10)$ y el nivel reducido uno de $70(80-10-0)$, reducirá el nivel y el resultado será eficiente. Esta regla brindará siempre los incentivos correctos. Siempre que a la sociedad le resulte conveniente que el nivel de actividad sea considerado por el agente dañador, un régimen de responsabilidad objetiva hará que él ajuste su conducta.

Esto se explica porque la responsabilidad objetiva opera sobre el agente dañador haciendo que interprete las medidas precautorias en un sentido amplio, incluyendo como un modo de reducción de la probabilidad de ocurrencia, o evitación del accidente, la limitación de su nivel de actividad. Los estándares de diligencia que emplean los tribunales suelen ser complejos, compuestos de muchas variables. Por ejemplo, en el caso de los conductores de automóviles, el estándar puede considerar relevante la velocidad a la que conducen, si mantienen el vehículo en condiciones, si respetan los semáforos, etc., pero en ningún caso incluyen el nivel de actividad. Ningún juez se pregunta si el conductor podía haber disminuido la probabilidad de ocurrencia del accidente limitando la cantidad de horas que conduce por día ${ }^{26}$. Por esta razón, cuando

\footnotetext{
encontrar ineficiente comprar un par de guantes para proteger sus manos cuando lava los platos en su casa. Pero si consiguiese un trabajo de lavaplatos y estuviese ocho horas por día realizando esa tarea, sin dudas lo óptimo sería que emplease los guantes.

26 LANDES y POSNER, 1987, p. 66. No obstante, esto no es del todo así. Muchas veces la normativa establece un número máximo de horas durante las cuales puede realizarse la actividad. Por ejemplo, en el transporte
} 
la regla es la negligencia, los agentes no tendrán incentivos para incorporar dentro de sus medidas la reducción de actividad. Pero la responsabilidad objetiva, al hacer que el agente internalice los costes del accidente, brinda incentivos para la limitación cuando ella es eficiente ${ }^{27}$.

\section{CRÍTICA A LA NATURALEZA RECÍPROCA DEL PROBLEMA COMO PARADIGMA DE LA RESPONSABILIDAD EXTRACONTRACTUAL}

\subsection{La incapacidad de dar cuenta de la práctica: el mito de la fórmula de HAND}

Los principales partidarios del AED pertenecen al ámbito del Derecho anglosajón. Por esta razón, cuando formulan sus tesis positivas lo hacen en relación con ese sistema jurídico. Ya vimos que POSNER cree que detrás de todas las doctrinas que lo conforman se esconde un análisis coste-beneficio, sintetizado en la fórmula de HAND, capaz de explicar las reglas básicas y las decisiones de los tribunales ${ }^{28}$.

R. W. WRIGHT, en un extenso y profundo trabajo, se ocupa de desenmascarar el mito de la fórmula de Hand. Afirma que la tesis según la cual la negligencia está definida en el Common Law a partir de un test agregativo consistente en un balance entre el riesgo y la utilidad social de la conducta (o un análisis coste-beneficio) no es más que un mito académico. Alega que el test casi nunca es mencionado por los tribunales, pero incluso cuando sí es mencionado en las sentencias rara vez es efectivamente aplicado. Según WRIGHT los pocos jueces que intentan realmente aplicarlo fracasan o terminan decidiendo el caso por razones de justicia distintas del análisis coste-beneficio ${ }^{29}$.

De ser esto así, ¿por qué razón es tan famosa la fórmula de Hand? ¿Por qué ha logrado tanta presencia en los textos jurídicos? La explicación de WRIGHT se relaciona con la historia del Derecho norteamericano. Una versión del test riesgo-utilidad irrumpe en el discurso jurídico explícitamente con la aparición del Restatement of the Law of Torts del American Law Institute de 1934, que hace referencia al riesgo irrazonable como aquel que supera al beneficio social de la actividad. Esta mención tuvo alguna influencia en los juristas, que comenzaron a citar el test al tratar el tema de la negligencia y la conducta razonable. Sin embargo, los tribunales seguían ignorándolo,

\footnotetext{
de larga distancia existen este tipo de restricciones. La violación de la norma determinará que la conducta del agente sea negligente. Pero esta consideración del nivel de actividad como parte de la diligencia debida no es uniforme en todos los ámbitos. Los jueces no se cuestionan, es cierto, si el agente podía haber disminuido eficientemente el nivel de riesgo utilizando su automóvil únicamente tres veces por semana y valiéndose de transporte público el resto de los días.

27 Esta conclusión ha sido cuestionada por GILLES, 1992, p. 329. Su argumento consiste en señalar que las categorías precaución y nivel de actividad no son mutuamente excluyentes. En muchas ocasiones es difícil saber si un individuo fue negligente o si su nivel de actividad fue excesivo. Por ejemplo, si alguien en un día de fuerte nevada decide ir a su trabajo en bicicleta en lugar de tomar el transporte público, uno puede considerar que fue negligente, o bien que el nivel de actividad óptimo era cero; o incluso, que fue negligente porque el nivel de actividad óptimo era cero: debió ir en transporte público y no en bicicleta. El autor analiza además distintos casos en los que evaluar la negligencia implica considerar el nivel de actividad. Creo que la crítica es interesante, pero daré por bueno el punto usualmente expuesto por el AED según el cual los tribunales tienen serias dificultades en incorporar la eficiencia del nivel de actividad en el estándar de diligencia.

28 Una exposición exhaustiva de esta tesis puede encontrarse en POSNER, 1972.

29 WRIGHT, 2003, p. 132.
} 
salvo por el juez L. HAND, casualmente uno de los fundadores del American Law Institute y activo participante en las discusiones de los varios Restatements. Además de él, casi ningún juez tenía en cuenta el test en esa época. Incluso, el propio HaND, en cerca de cinco décadas de ejercicio de su función, sólo se refirió a la fórmula en 11 casos de negligencia entre 1938 y 1949, época en la que estaba más comprometido con su actividad en el instituto. Según se especula, la mención de la fórmula en estos casos estaba ligada a su interés por fomentar el Restatement, que incluía una versión poco sofisticada del test ${ }^{30}$. Así y todo, ni siquiera en la primera mención del test, en el caso Gunnarson vs. Robert Jacob, Inc. ${ }^{31}$. HAND aplicó coherentemente la fórmula. Lo que hizo fue expresar que la negligencia depende de un balance entre el riesgo y la utilidad de la conducta, pero luego asumió que fue exclusivamente negligente una de las partes aun cuando existían razones para considerar que la otra tenía un mayor conocimiento de los riesgos involucrados, lo que en términos de CALABRESI implica que era el evitador más económico del daño y por ello debió ser responsabilizado. Concluye WRIGHT que el resultado de este caso no puede explicarse por la fórmula de HAND $^{32}$. Asimismo, en otra oportunidad HAND reconoció que la implementación de la fórmula requiere información que es inaccesible, por lo que la cuestión del cuidado razonable debería ser decidida por el jurado en base a los «estándares comúnmente aceptados» ${ }^{33}$.

Todo esto evidenciaría que la proyección de la fórmula de HAND en el Derecho anglosajón es engañosa y su relevancia académica puramente anecdótica. En parte, su fuerza vendría dada por el hecho de que quienes simpatizan con el análisis económico ostentan importantes cargos institucionales. Así, observa O. FISs que muchos de los miembros del movimiento del AED — como R. Posner, F. EAsterbrook, R. Winter y R. BORK - fueron designados por Ronald Reagan en la justicia federal y, por tanto, lograron una influencia mayor que la alcanzada por cualquier miembro de la escuela crítica del Derecho ${ }^{34}$. Obviamente, el hecho de que la escuela crítica tenga escasos representantes en el poder judicial no es suficiente para afirmar que por esta razón el AED se impone como corriente dominante. Lo único que deseo enfatizar es que el prestigio del que gozan académicos tan respetados como los recién mencionados se ve reforzado por el doble rol que cumplen como profesores y miembros del poder judicial. Desde esta última posición también impactan sobre la academia, especialmente en un sistema como el Common Law. Teniendo esto en cuenta, es plausible afirmar que el crecimiento del AED a partir de la década de los ochenta puede haber sido favorecido por estas designaciones.

Las interpretaciones de POSNER que consagran a la fórmula de HAND como el principio fundamental del Derecho de daños también son objeto de crítica por parte de Wright. Puntualmente critica que Posner, tanto en su trabajo A Theory of Negligence como en The Economic Structure of Tort Law - este último en colaboración con W. LANDES - ${ }^{35}$ no discute seriamente los hechos de ninguno de los 1.528 casos que

\footnotetext{
30 WRIGHT, 2003, pp. 10-14.

3194 F. 2d 170 (2d Cir. 1938).

32 WRIGHT, 2003, pp. 20-21.

33 WRight, 2003, p. 22.

34 FISs, 1986, p. 2.

35 Ambos trabajos ya citados.
} 
afirma haber analizado. En particular, cuando se explaya sobre el caso Carroll Towing, que expresa la fórmula en términos matemáticos, POSNER describe incorrectamente los hechos, confundiendo varias cuestiones relacionadas con el actor y el demandado, los daños que se reclamaban y los hechos por los que se evaluó la negligencia, entre otras cosas. Del mismo modo critica la vaguedad y la parcialidad de las citas jurisprudenciales que LANDES y POSNER seleccionan para sus análisis y las conclusiones que extraen a partir de interpretaciones totalmente sesgadas de las palabras de los jueces ${ }^{36}$. Las críticas de WRIGHT son sumamente elaboradas e interesantes, aunque en algunas ocasiones parecen excesivas. No obstante, pese a que su lectura de la obra de LANDES y POSNER es poco caritativa, el autor logra a mi juicio poner en jaque definitivamente las pretensiones descriptivas del AED.

Dado lo dicho hasta aquí, ¿por qué insisten los partidarios del AED en sostener tesis positivas como la de POSNER? Creo que el imperialismo de la ciencia económica ${ }^{37}$, que expande sus fronteras abarcando cada vez más campos de estudio, ha llevado a los economistas a asumir un fuerte compromiso con los fundamentos teóricos de su disciplina. Este compromiso, seguramente desmedido, les hace ver el mundo a través del prisma del análisis coste-beneficio, lo que les genera una ilusión de inmanencia del principio de eficiencia. Terminan analizando desde esta perspectiva todas las cuestiones de la vida, incluso aquellas que nunca pensaríamos desde el sentido común como una cuestión económica. Ejemplo de ello es la interpretación de POSNER del delito de violación. Según este autor se prohíbe la violación simplemente porque existe un mercado sexual y el violador lo evade. Uno puede casarse, tener una novia o incluso recurrir a la prostitución para conseguir sexo, es decir que el sexo es un bien que se ofrece en el «mercado»; sin embargo, el violador lo «roba» en lugar de pagar por él, lo que evidentemente impide la maximización de la riqueza. Sólo por esta razón debe prohibirse la conducta ${ }^{38}$.

Esta interpretación del delito de violación es tan absurda que resulta difícil creer que sea sostenida por un intelectual de la talla de R. POSNER. Las pretensiones universalistas del AED no respetan ningún límite y la disciplina sufre necesariamente de un defecto en cuanto a su esfera de incumbencia. Que la violación pueda ser entendida en términos económicos como un acto ineficiente, dada la definición de eficiencia, es algo muy distinto de afirmar que la violación se prohíbe porque es ineficiente. Los partidarios del AED parecen convertir todos los enunciados del primer tipo en enunciados del segundo. Por supuesto, considerando que las sociedades no son clubes de suicidas, el Derecho de daños generalmente podrá ser interpretado en base a criterios de eficiencia. Es razonable sostener que una sociedad que perdura en el tiempo y pretende continuar su existencia no cuenta, ni puede contar, con un sistema de responsabilidad extracontractual ineficiente, por ejemplo, en el que los daños no son compensados. Pero de allí no puede extraerse como conclusión que la sociedad persigue a través del Derecho de daños la maximización de la riqueza.

36 WRIGHT, 2003, pp. 41-42.

37 Sobre las razones esgrimidas por los economistas que explican por qué ellos se han trasladado a otros campos de estudio en lugar de que los sociólogos, por ejemplo, se trasladen a la economía, vid. BRENNER, 1980, p. 183.

38 POSNER, 1998, p. 238. 
Para alguien como POSNER, que define la economía como el estudio de la conducta humana racional, no hay ámbitos excluidos del análisis ${ }^{39}$. Es cierto que toda conducta puede ser analizada económicamente desde este punto de vista, ya que toda acción implica un coste, aunque sea un coste de oportunidad; pero de allí no se sigue, como parecen suponer algunos autores, que en todos los ámbitos de la vida los individuos se comporten como maximizadores de utilidad. Puede ocurrir que algunas de sus conductas sean incidentalmente maximizadoras, pero ello no demuestra que puedan ser explicadas o comprendidas a la luz del criterio de eficiencia. Para comprender lo que el individuo hace, una ciencia de la conducta humana racional debe apelar, entre otras cosas, a la intención. Por ello es relevante lo que el individuo se ve a sí mismo realizando cuando actúa. De esta manera, es posible que su conducta maximice la riqueza, y que a la vez sea un error explicarla a partir del principio de maximización ${ }^{40}$.

En definitiva, las aspiraciones descriptivas del AED se quedan a mitad de camino al intentar elaborar una teoría comprehensiva que explique el mundo a la luz del principio de eficiencia. Si sus enunciados fuesen más modestos y se limitasen a corroborar en qué medida ciertas normas son compatibles con la eficiencia y cuáles no lo son, sus conclusiones serían mucho más acertadas y útiles para comprender cabalmente el Derecho de daños.

\subsection{El riesgo y la acción incorrecta}

Al estudiar las reglas de responsabilidad expliqué que la diferencia entre la regla de negligencia y la de responsabilidad objetiva es que la segunda carga al agente dañador con el coste del accidente aun cuando haya adoptado las medidas precautorias «óptimas». La razón por la que se hace responsable a quien no pudo obrar con mayor diligencia tiene que ver con que ésta es una manera de brindarle los incentivos necesarios para que regule su nivel de actividad, cuando es deseable que la controle. En otras palabras, de ser eficiente que el agente reduzca su nivel de actividad, el modo de conseguir ese resultado es haciéndolo objetivamente responsable.

Vimos, sin embargo, que la reducción del nivel de actividad puede ser considerada una forma más de precaución. Incluso algunos autores entienden que una conducta puede ser descripta como negligente o como un exceso de actividad. De hecho, toda conducta negligente es por definición un exceso: el nivel eficiente de actividad negligente es cero, que es lo mismo que decir que debió ser omitida ${ }^{41}$. Esta observación es relevante porque si, como sugiere SHAVELL, la incapacidad de los tribunales de incorporar el nivel de actividad de las partes en el estándar de negligencia es un defecto de la regla de la culpa ${ }^{42}$, esto significa que sustantivamente no hay una diferencia entre esta regla y la de responsabilidad objetiva: la regla de la culpa en condiciones ideales

39 POSNER, 1979b, p. 287.

40 La explicación de lo que un individuo hace no se limita al estudio de sus intenciones. Es posible que un individuo haga algo pese a que no tenía la intención de hacerlo. No obstante, cuando la descripción externa de sus actos coinciden con sus intenciones, la mejor explicación radica en lo que el propio individuo se ve a sí mismo realizando.

41 Vid. la opinión de S. GILLES en la nota 24.

42 Shavell, 1987, p. 24. 
incluye el nivel de actividad de las partes, por lo que la única diferencia con la regla de responsabilidad objetiva estaría dada por quién resulta responsable residualmente. Con la regla de culpa, el responsable residual será la víctima y con la regla de responsabilidad objetiva será el agente dañador.

Si esto es correcto, de aquí se sigue que para el AED la distinción entre la responsabilidad objetiva y la culpa es puramente formal y no sustancial, pese a que en nuestro uso habitual del lenguaje reconocemos que la culpa es una categoría distinta de la conducta riesgosa. La culpa se asocia a una idea de incorrección de la acción, de conducta probibida, mientras que la responsabilidad objetiva se relaciona con conductas que estando permitidas generan riesgos hacia terceros. La generación de niveles normales de riesgo no puede ser considerada desde ningún punto de vista como una acción incorrecta. Sólo en algunos casos es incorrecto realizar conductas riesgosas. Explica JAKOBS que «puesto que una sociedad sin riesgos no es posible y nadie se plantea seriamente renunciar a la sociedad, una garantía normativa que entrañe la total ausencia de riesgos no es factible; por el contrario, el riesgo inherente a la configuración social ha de ser irremediablemente tolerado, como riesgo permitido» ${ }^{43}$.

Pero estas categorías no interesan al AED. Lo único relevante es el coste esperado de un accidente y el beneficio que se obtiene de la actividad que causa el daño. Así, para un partidario de esta escuela debe disuadirse tanto al taxista que conduce diligentemente 12 horas por día, es decir, observando las normas de tránsito, como a quien conduce una vez a la semana negligentemente, si es que el valor esperado del daño y el beneficio que obtienen las partes de su actividad fuese idéntico en ambos casos. Supongamos que un taxista conduce cuatro horas más cada día para obtener un beneficio anual extraordinario de 40. Su actividad implica una probabilidad del 10 por 100 de generar daños por 1.800, por lo que anualmente el valor esperado de los daños es de 180. Imaginemos que puede reducir la probabilidad de causar daños por 1.800 al 7,5 por 100 renunciando al número de horas extraordinarias. En este caso el valor esperado de los daños será de 135. Como el beneficio marginal que obtiene es sólo de 40 y la reducción de daños esperados es de 45, lo óptimo será que limite su actividad.

Supongamos, por otra parte, que Jordi conduce una sola vez a la semana pero a gran velocidad, superando el límite establecido por las normas de tránsito. El beneficio que obtiene de su actividad también es de 40, es decir, que aceptaría no conducir a alta velocidad a cambio de esa cantidad de dinero. Imaginemos que con su nivel de actividad genera una probabilidad del 90 por 100 de causar daños por 200. El valor esperado del daño es 180. Digamos que si conduce dentro de los límites de velocidad permitidos la probabilidad de ocasionar ese volumen de daños es del 2 por 100, dado que sólo conduce una vez a la semana. Lo eficiente es también en este caso que Jordi se comporte diligentemente (o reduzca su nivel de actividad negligente a cero).

Estos dos ejemplos demuestran que dos conductas, una permitida pero realizada muy frecuentemente (como la del taxista) y otra negligente pero infrecuente (como la de Jordi) son idénticas desde el punto de vista económico. Ambas son conductas ineficientes; ambas deben ser disuadidas. Ninguna otra consideración es relevante para el AED. Sin embargo, la acción del taxista es distinta de la acción de Jordi. La del taxista

\footnotetext{
${ }^{43}$ JAKOBS, 2002, p. 44.
} 
es una acción diligente y, desde el punto de vista moral, al menos no es incorrecta. En cambio, la acción de Jordi es negligente y moralmente incorrecta ${ }^{44}$. Esta distinción no se ve reflejada en el modo en que el AED trata a las conductas. Toda conducta ineficiente, correcta o incorrecta, debe ser desincentivada.

Un punto similar puede señalarse respecto de la teoría de los daños punitivos. Estos daños, que son otorgados muy excepcionalmente por los tribunales de los Estados Unidos, tienen por finalidad castigar ciertas conductas intencionales o temerarias en el agente dañador. Se entiende que están diseñados para expresar la desaprobación de la conducta del demandado ${ }^{45}$. No obstante, para el AED deben imponerse daños punitivos cada vez que la probabilidad de que el agente sea condenado por los daños que causa sea inferior al 100 por $100^{46}$. Si un individuo puede causar un daño de 1.000.000, con una probabilidad del 1 por 100, y sólo hay una probabilidad del 10 por 100 de que sea condenado a indemnizar cuando causa el daño, el AED recomendaría que el monto indemnizatorio no se corresponda con el valor de daño sino con un valor diez veces superior, o sea, de 10.000.000. Ello es así porque, con estos valores, el agente dañador sólo tomará medidas precautorias cuando ellas sean inferiores a 1.000, que es el coste esperado que enfrenta. Como dije, el daño es de 1.000.000, aunque la probabilidad de su ocurrencia es de 0,01, por tanto el daño esperado es de 10.000. Pero la cuestión no termina allí. Como el agente sabe que sólo será condenado el 10 por 100 de las veces, su coste esperado en indemnizaciones es solamente de 1.000. Para evitar que el agente tome medidas precautorias ineficientes, esto es, tomando como referencia los 1.000 que enfrenta como indemnización y no los 10.000 de daños esperados que genera, debería imponérsele como daños compensatorios la cantidad de 1.000.000 y como daños punitivos la cantidad de 9.000.000. De este modo se logra el efecto deseado: la disuasión óptima. Cuando la indemnización se fija en 10.000.000, el valor esperado de la condena que enfrenta el agente es de $10.000^{47}$, y éste es el límite de las medidas precautorias que debe estar incentivado a tomar. Esta recomendación tiene por efecto conseguir que el agente dañador tome medidas precautorias óptimas, y desde el punto de vista analítico es admisible.

Pese a todo, en la idea de condenar a pagar 10.000.000 a quien genera una probabilidad del 1 por 100 de causar daños por 1.000.000 hay algo que nos incomoda. Además, nos parece problemático que 9/10 partes de la indemnización sean a título de castigo cuando el agente dañador realiza una acción tan poco riesgosa. Es más, la idea de daños punitivos, tal como es presentada por el AED, no se restringe a las indemnizaciones por acciones negligentes o acciones prohibidas ${ }^{48}$. Siempre que no

44 Es cierto que una conducta es negligente cuando la norma jurídica así lo establece y, entonces, muchas conductas podrían ser calificadas como negligentes sin ser moralmente incorrectas. Esto podría deberse a un error del legislador. Sin embargo, lo relevante para mi argumento es que la regla de la negligencia intenta capturar la incorrección de la acción. A diferencia de la responsabilidad objetiva, donde lo primordial es un determinado resultado indeseable, la regla de la negligencia se basa en una actitud crítica hacia la conducta del agente, una desaprobación de lo que el individuo bace.

45 CANE, 2006, pp. 173-174.

46 PolinKsy y SHavell, 1998, pp. 887-896.

47 Este valor surge de ponderar los 10.000.000 que se fijan como indemnización por la probabilidad de que ocurra el daño $(0,01)$ y por la probabilidad de que el agente sea condenado en el juicio $(0,1)$.

48 Justamente los partidarios del AED afirman que los daños punitivos no son un castigo, pero en nuestro lenguaje ordinario, ¿de qué otro modo denominaríamos a la obligación de pagar una suma de dinero que excede el valor de la compensación? 
haya certeza de que el agente vaya a ser condenado cuando causa un daño, aunque la acción realizada esté permitida, los daños punitivos son recomendados por la teoría. Nuevamente, se deja absolutamente de lado la distinción entre la corrección y la incorrección de la acción. Según el AED los individuos pueden ser castigados aunque sus acciones no sean incorrectas, y esto es contraintuitivo ${ }^{49}$. Ninguna consecuencia tan gravosa para un individuo puede seguirse de una acción que de ningún modo es incorrecta.

Otra cuestión relevante que el AED pasa por alto es que debería observarse cuál es el motivo de que la probabilidad de ser condenado sea inferior al 100 por 100. Si se debe a una ineficiencia del Estado que omite controlar, parece extraño que ello amerite un castigo para el agente dañador. En cambio, si se debe a que el propio agente realizó conductas tendentes a disimular su conducta para disminuir la probabilidad de ser detectado, la idea de daños punitivos se torna atractiva. Pero el AED ignora esta distinción y recomienda aumentar el monto indemnizatorio en todos los casos. Estos daños deberían imponerse sólo cuando hay una conducta tendente a evadir la condena o cuando se determina que el agente obró tomando en cuenta la baja probabilidad de ser penado y no el valor esperado del daño ocasionado por su acción.

Es verdad que los trabajos de análisis económico sobre daños punitivos suelen ser normativos; no pretenden describir las circunstancias en las que los tribunales imponen esta penalidad sino que definen las circunstancias en las que deberían imponerla. En otras palabras, proponen una fórmula para que se otorguen daños punitivos con el fin de brindar los incentivos correctos al agente dañador. Sin embargo, al ser una tesis normativa puede apreciarse aún mejor que la distinción entre acción correcta e incorrecta es irrelevante para el AED. Ello es así porque no importa que la acción sea correcta, sino que lo único a considerar es que la probabilidad de ser condenado que enfrenta el agente dañador sea inferior al 100 por 100. Es decir, bajo esta propuesta normativa se esconde una determinada concepción del Derecho de daños. Según esta concepción, el Derecho es un instrumento para reducir los costes de los accidentes, con independencia de que estos resulten de conductas correctas o incorrectas. El entramado conceptual utilizado por el economista para estudiar la responsabilidad extracontractual prescinde de estas categorías. En este sentido, no puede tratarse de una buena explicación interna.

Esto es así porque cuando el AED propone este tipo de interpretaciones de la regla de responsabilidad objetiva, de la negligencia y de los daños punitivos está pidiendo a los teóricos que abandonen una distinción que es esencial en la comprensión de nuestras relaciones sociales. La comprensión habitual de la moralidad se basa en esta distinción, en la idea de que ciertas cosas no deben realizarse. En palabras de FrIED, la distinción entre lo correcto y lo incorrecto es el fundamento de nuestra personalidad moral. Nada de lo que hacemos, de las decisiones que tomamos o de las cosas que ele-

49 En los Estados Unidos hay estudios que indican que los individuos en general, y los jueces y los jurados en particular, muestran una fuerte reticencia a condenar por daños punitivos cuando la conducta del agente no es incorrecta. La principal función de los daños punitivos consiste en castigar por la realización de conductas reprobables. El hecho de que el agente esté sujeto a una probabilidad menor al 100 por 100 de ser hallado responsable es irrelevante para la concesión de daños punitivos. Ello demuestra dos cosas: por un lado, que la distinción entre lo correcto y lo incorrecto es relevante y, por otra parte, que las tesis descriptivas del AED no son acertadas. Vid. SunSteIn, SCHKAdE y KAHNEMAN, 2002. 
gimos es más importante que el fundamento, basado en la corrección y la incorrección, de estas acciones, decisiones o elecciones que realizamos ${ }^{50}$.

Por estas razones, entiendo que el AED no reconstruye adecuadamente nuestras intuiciones esenciales respecto de la responsabilidad por actos lícitos e ilícitos. La responsabilidad objetiva y la culpa son categorías distintas, porque distinguir lo correcto y lo incorrecto es relevante para nuestra comprensión del mundo. Esto significa que el AED no describe correctamente el hecho de que los sistemas jurídicos distinguen entre acciones correctas e incorrectas asignando consecuencias diferentes a cada una de ellas ${ }^{51}$. Su esquema conceptual no logra capturar lo relevante de estas categorías. Sólo puede explicar la diferencia a partir de un defecto de información al elaborar el estándar de cuidado debido. Pero el punto de la práctica es distinto: la corrección y la incorrección son categorialmente distintas, no son expresiones de un mismo principio en diferentes circunstancias.

\subsection{La irrelevancia de la causalidad}

\subsubsection{Los orígenes: COASE y CALABRESI}

Aceptar que el fenómeno de los daños es de naturaleza recíproca, como sugiere COASE en The Problem of Social Cost, implica negar la relevancia de los procesos causales. Decía COASE, para el caso de actividades rivales, que evitar el daño a B supone causar daño a A. Según esta visión, la idea de un agente dañador que causa un perjuicio a la víctima carece de sentido ya que ambos son conditio sine qua non del resultado. Lo determinante a la hora de asignar el derecho a ser compensado es conocer el valor de lo que se obtiene y el valor de lo que se sacrifica para conseguirlo ${ }^{52}$.

Posteriormente, siguiendo esta misma línea, CALABRESI reconoce en The Costs of Accidents que su uso de la palabra «causa» es engañoso y que no considerará qué significa - si es que la expresión tiene algún sentido- decir que una actividad causa un determinado accidente ${ }^{53}$. El desprecio por la causalidad como presupuesto de la responsabilidad extracontractual toma su forma más cruda en afirmaciones del tipo «si el fabricante de televisores es el evitador más económico de los accidentes de tránsito, él debe ser responsabilizado». Es cierto que normalmente no será el evitador más económico alguien que no guarda ninguna vinculación causal con los hechos del accidente pero, si por alguna razón lo fuese, el AED no tendría problemas en hacerlo responsable.

La primera objeción que uno puede plantear a una teoría que, siendo una teoría de la responsabilidad extracontractual, no recoge el requisito de causalidad como relevante es que falla al describir la práctica y las categorías empleadas usualmente

50 FRIED, 1978, pp. 7-8.

51 Por ejemplo, la extensión de la reparación puede variar según se trate de actos lícitos o ilícitos; el sistema de seguro puede ser impuesto obligatoriamente para los casos de responsabilidad objetiva, mientras que suele ser voluntario en los casos de culpa e inconcebible para los daños causados dolosamente, etcétera.

52 COASE, 1960, p. 2.

53 CAlabRESI, 1970 , p. 6, nota 8. 
en el discurso del Derecho de daños. En el discurso habitual, prescindir de la idea de causa implica renunciar a identificar un agente dañador y una víctima. Alguien es agente dañador cuando causa un daño ${ }^{54}$. No es suficiente que reúna ciertas características, como ser rico, pobre o estar en condiciones de evitar el daño de modo más económico.

No obstante, sólo para continuar con el argumento, supongamos que fuese posible identificar a dos individuos como dañador y víctima, independientemente de la causalidad, a partir de alguna característica especial. Digamos que la víctima es aquella que sufre un menoscabo en sus intereses y que el agente dañador es aquel que está en condiciones de impedir ese menoscabo a un coste menor que otros individuos, incluida la víctima ${ }^{55}$. Aun así, el sentido común nos indica que debe haber una razón para vincular a ambas partes entre sí. Esta razón, en el Derecho de daños, es la relación de causalidad. El agente dañador está vinculado con la víctima porque causó el daño. Este requisito de causalidad, dice FEINBERG con gran sencillez, no es más de lo que en el discurso práctico ordinario quiere significarse con frases tales como «el daño de $\mathrm{B}$ ocurrió debido a la acción de A» $\mathrm{O}$ «como consecuencia de la acción de A, $B$ fue dañado» ${ }^{56}$.

Ahora bien, ¿es suficiente para vincular al dañador con la víctima el hecho de que el primero puede evitar el daño de un modo más económico? Usualmente los sistemas de responsabilidad civil consideran irrelevantes los costes de evitación para vincular a dos sujetos, es decir, para vincular a la víctima con uno de los muchos sujetos que podrían ser vinculados con ella. La vinculación siempre viene dada por alguna forma de causalidad. El AED podría entonces renunciar a su pretensión de prescindir de la causalidad e interpretar que el evitador más económico, que omite intervenir para que la víctima no sufra el menoscabo, causó el daño. Esta noción de causalidad sería demasiado amplia y contraria a lo que se interpreta como causación por omisión. Las omisiones son problemáticas, como explican HART y HONORÉ, porque uno puede considerar que es causa de la muerte de una planta la omisión del jardinero que no la regó, pero también la de cualquier otra persona que tampoco la haya regado ${ }^{57}$. Supongamos que los costes de regar la planta sean idénticos para el jardinero y para todo transeúnte. Imaginemos que la planta está en un jardín público y que la regadera está a la mano de cualquiera. En esas condiciones ¿qué razón tenemos para vincular al jardinero y no a cualquier otro individuo que haya pasado frente a la planta? El AED haría responsable a cualquiera de los transeúntes, incluyendo al jardinero como uno más. Pero en el discurso ordinario la razón por la que la omisión del jardinero es la única causa de la muerte de la planta tiene que ver con que su omisión es anormal en ese contexto. Es parte de la rutina — del escenario habitual— que el jardinero se encargue de regar la planta, y es perfectamente normal que el resto de los individuos omitan regarla ${ }^{58}$.

${ }^{54}$ Causar un daño es condición necesaria pero no suficiente para que alguien sea considerado agente dañador. En general, los ordenamientos jurídicos exigen la concurrencia de algún factor de atribución como la culpa o el riesgo.

55 Esta idea es defendida en Posner, 1990, p. 328.

56 FEINBERG, 1984, pp. 118-119.

57 HART y HONORÉ, 1985, pp. 37-38.

58 HaRT y HonORÉ, 1985, p. 38. 
Además, los juicios causales tienen una pretensión explicativa que la noción de evitador más económico no puede satisfacer. ROSENKRANTZ expone este punto al afirmar que «el hecho de que A sea el evitador más barato de costes, dado que puede prever el accidente y puede asegurarse contra él del modo más económico, es un asunto absolutamente tangencial desconectado de la cuestión de si el accidente puede ser descripto como algo hecho por A. Por consiguiente, pensar, como CALABRESI, que todos los juicios causales dependen de juicios de eficiencia es sencillamente un error de categoría» ${ }^{59}$.

Piénsese en el caso de Álvaro que, tomando un café en un bar, observó detenidamente los siguientes hechos: Sergio al ingresar al establecimiento dejó su paraguas junto a la puerta. Se dirigió al baño y un mozo, para evitar que se mojase la entrada, tomó el paraguas y lo guardó en un lugar más apropiado. Inmediatamente después entró Mateo y apoyó su paraguas, que era casi idéntico al de Sergio, también junto a la puerta. Cuando Sergio salió del baño tomó el paraguas de Mateo y se retiró. Álvaro podría haber evitado la confusión de Sergio a un coste muy bajo, simplemente avisándole que el paraguas que se estaba llevando no era el suyo. Por su parte, Sergio no tenía forma de percatarse a un coste razonable de que el paraguas era ajeno, ya que el de Mateo era muy similar y estaba ubicado en el mismo sitio en el que minutos antes había dejado el propio. Cuando Mateo salió del baño se retiró pensando que le habían hurtado el paraguas. Álvaro, tampoco dijo nada en esta oportunidad. ¿Significa esto que Álvaro, por ser el evitador más económico, fue el causante de la confusión y, en última instancia, del daño? Evidentemente no. El uso común de nuestros conceptos causales no nos permite describir la pérdida del paraguas de Mateo como algo hecho por Álvaro.

Lo que quiero discutir aquí es la noción de causalidad basada en la idea de poder evitar el daño de modo más económico, una idea que no resulta convincente en absoluto. Ello sin perjuicio de seguir reconociendo que seguramente el causante coincidirá en muchos casos con el evitador más económico, pero no es causante por esa razón.

En conclusión, si el AED pretende prescindir de la idea de causalidad no podrá dar cuenta de que en el Derecho de daños existe una víctima y un agente dañador especialmente vinculados por el hecho de que el segundo causó un daño al primero. Ahora, si pretendiese eludir esta crítica apelando a la causación por omisión de quien era el evitador más económico del daño, el argumento no se sostiene por las razones recién explicadas.

\subsubsection{La causalidad al servicio de los objetivos del Derecho de daños}

Consciente de que el problema de la causalidad no podía ser ignorado eternamente por los estudios de análisis económico, en 1975 CALABRESI escribió un trabajo ${ }^{60}$, que se convertiría en clásico, en el cual intenta encontrar una justificación económica a la exigencia de causalidad. Se pregunta qué papel juega el lenguaje causal para alcanzar los objetivos del Derecho de daños. En última instancia, cree CALABRESI, el requisito de causalidad debe ser justificado en términos funcionales, esto es, por el servicio que

\footnotetext{
59 Rosenkrantz, 2005, p. 22.

60 Calabresi, 1975.
} 
presta a las necesidades humanas. Desde esta perspectiva, afirma que muchas discusiones filosóficas aparentemente significativas acerca de la causa son irrelevantes para el uso jurídico del término. Por ejemplo, en el ámbito del Derecho, la causa de una enfermedad depende de cómo, en un determinado momento, puede ser controlada más fácilmente ${ }^{61}$.

Las nociones causales que CALABRESI analiza son tres: la vinculación causal, la conditio sine qua non y la causa próxima. El primer concepto es totalmente empírico. Hay vinculación causal entre un acto o actividad y un daño cuando puede concluirse sobre la base de la evidencia disponible que la ocurrencia del acto o actividad incrementa las probabilidades de que ocurra el accidente. La conditio sine qua non identifica la causa como aquella condición sin la cual el daño sería imposible que se concrete. Por último, la proximidad causal se relaciona con la previsibilidad del resultado. Hay proximidad causal entre un acto $\mathrm{X}$ y un resultado $\mathrm{Z}$ cuando era previsible que la realización de $\mathrm{X}$ traería como consecuencia un estado de cosas $Z$. Veamos cómo sirven estos conceptos causales a cada uno de los objetivos del sistema.

Una de las principales metas es la reducción de los costes primarios. Estos están dados por la cantidad y la gravedad de los accidentes y pueden reducirse por medio de la disuasión general o de la disuasión específica. De acuerdo con la disuasión general o método de mercado - que consiste en hacer responsable a aquel que está en mejor posición para decidir si el coste de evitación es menor que el coste del daño- la vinculación causal debería ser exigida ya que parece difícil que alguien pueda ser el evitador más económico de un daño si sus acciones no incrementan las probabilidades de que ocurra el accidente. Sin embargo, el mismo CALABRESI reconoce que alguien puede estar mejor posicionado para realizar el análisis coste-beneficio de la actividad y para influir en la conducta de los individuos sin estar involucrado directamente en el accidente, es decir, sin estar causalmente vinculado ${ }^{62}$. Éste es el caso de la confusión de paraguas que relaté en el apartado IV.3.1. En principio, entonces, no sería necesario a los fines de la responsabilidad extracontractual, tal como la concibe el AED, que las conductas de los individuos incrementen el riesgo de que se produzca el daño, aunque CALABRESI no lo admita claramente.

La exigencia de que la acción del individuo sea conditio sine qua non del daño se justifica porque carecería de sentido intentar incentivar a quien no impacta de ningún modo en la producción del resultado ni puede hacer nada para modificar las conductas de los involucrados. No obstante, tanto la conditio sine qua non y la vinculación causal dependen de la proximidad causal para que el método de mercado sea efectivo. Nótese que sin previsibilidad el individuo no podrá comparar los costes de los daños con los de las medidas precautorias necesarias para evitarlos. En este sentido, la proximidad causal es funcional a la consecución de este objetivo.

Siguiendo con los métodos, al considerar la disuasión especial o método colectivo debe advertirse que la vinculación causal tiene perfecto sentido exigirla, pero no así la conditio sine qua non. La disuasión especial consiste en prohibir (penalizar) una determinada actividad. Por ello, sólo parece razonable prohibir actividades que incre-

\footnotetext{
61 Calabresi, 1975, p. 105.

62 Calabresi, 1975, p. 85, nota 21.
} 
menten el riesgo de daño y no otras. Sin embargo, como son muchas las actividades que incrementan el riesgo de daño, el criterio sine qua non no es convincente para imponer una prohibición. Seguramente habría un exceso de actividades prohibidas. Esta noción causal no ofrece guía para seleccionar, del universo de acciones causalmente vinculadas con el accidente, cuál debe ser colectivamente disuadida. La proximidad causal, en cambio, sí es necesaria porque es importante penalizar sólo aquellas acciones cuya propensión a generar daños puede ser conocida por los destinatarios de la norma antes del accidente. De otro modo, la penalización no podría alterar los incentivos de los individuos.

Finalmente, la otra gran meta que postula CALABRESI es la reducción de los costes secundarios. Estos se relacionan con la concentración del daño en pocas personas o con el hecho de que el que sufre el daño no esté en las mejores condiciones para absorberlo, por contar con un bajo ingreso o un escaso nivel de riqueza ${ }^{63}$. Los métodos para reducir estos costes son la dispersión y la distribución del daño, y en estos casos los conceptos causales son mucho más difíciles de justificar económicamente. Ya sea para que el daño sea asumido por la mayor cantidad de gente posible (dispersión) como también para que sea soportado por quien se encuentra en mejores condiciones económicas de hacerlo (distribución) —o sea el que más ingreso y riqueza posee- la vinculación causal y la conditio sine qua non son conceptos totalmente inútiles. Ninguna de estas nociones causales nos ayuda a lograr estos objetivos ${ }^{64}$. La proximidad causal, en cambio, puede ser importante exigirla a los fines de identificar a aquel que puede dispersar de modo más económico. Es decir, haciendo responsable a quien puede prever el daño y su magnitud se maximizan las posibilidades de que este individuo pueda contratar un seguro. Contrariamente, quien no puede prever difícilmente pueda tomar un seguro a coste razonable. No puede decirse lo mismo, por supuesto, respecto del objetivo distribución. Aquí ninguno de los conceptos causales es relevante. Ninguno de ellos garantiza que se indique como causante a quien está en mejor condiciones económicas de asumir el daño. Como siempre, CALABRESI apela a la idea de que se debe lograr la mejor combinación de objetivos a fin de minimizar del coste total de los accidentes.

¿Es satisfactoria esta reconstrucción económica de los conceptos causales? La sensación que produce el trabajo de CALABRESI es que el AED, enfrentado a la tarea de explicar el rol de la causalidad, ha deformado los conceptos tradicionales para poder hacerlos entrar a la fuerza en el contexto de los objetivos de la responsabilidad extracontractual enunciados en The Costs of Accidents. En realidad, si se sigue estrictamente el análisis económico, la proximidad causal no funciona como expone CALABRESI. Es suficiente con advertir que respecto de la dispersión del daño, señala WRIGHT, no existe una conexión necesaria entre la parte que causa el daño y quien puede dispersarlo o absorberlo una vez que ha ocurrido ${ }^{65}$. La proximidad causal es un límite a la respon-

${ }^{63}$ En realidad, CALABRESI describe un objetivo general que es la minimización de la suma de costes primarios, secundarios y terciarios. Los dos primeros ya fueron explicados, mientras que el último carece de sentido analizarlo a los efectos de este trabajo. Diré solamente que los costes terciarios son los costes de administrar el sistema de responsabilidad civil.

${ }^{64}$ En rigor, aunque CALABRESI no lo considera, podría sostenerse que la conditio sine qua non sirve a la dispersión del daño porque usualmente con este criterio podrá conectarse con el daño a una multiplicidad de personas. De todos modos, es esperable que los costes administrativos de hacerlo sean prohibitivos.

65 WRIGHT, 1985, p. 440. 
sabilidad de quien actúa: sólo se responderá por los daños que fuesen previsibles de acuerdo con la acción realizada. Pero a los fines de la dispersión no es necesario que se responsabilice al actor, sino simplemente a quien pudo prever el daño y tomar un seguro. Entonces, o bien el rol de la proximidad causal no está correctamente descrito por CALABRESI desde el punto de vista económico, porque debería incluir a cualquiera en condiciones de asegurarse, o bien tal como es aplicado este concepto por el sistema jurídico no sirve a la satisfacción de objetivos económicos.

Lo mismo puede decirse de la causa próxima en relación con el método de mercado. El que puede tomar las medidas a menor coste necesariamente debe poder prever el daño, pero no necesariamente debe ser el causante en el sentido jurídico del término, como demuestra el ejemplo de la confusión de paraguas. Corresponde aclarar de todos modos que aunque estuviese bien descripta en términos económicos, la proximidad dejaría de ser la misma idea empleada por los tribunales, porque para satisfacer los criterios de eficiencia debería desvincular a quien realiza la acción de aquel que puede tomar medidas o asegurarse de modo más económico. Esto no sería relevante si CALABRESI no pretendiese explicar la noción tradicional en función de los objetivos de la responsabilidad extracontractual.

Siguiendo la misma idea, creo que el problema que subyace a su explicación es que no toma en cuenta las categorías tal como son empleadas por los juristas. De haberlo hecho, advertiría que una interpretación de la causalidad en términos de costes y beneficios es inviable. Una visión semejante olvida que en materia de causación las cosas no son tan sencillas. CALABRESI piensa que puede analizar la causalidad en el Derecho de daños partiendo de conceptos causales muy simplificados. Así, al reducir la idea de proximidad causal a la previsibilidad del resultado se disocia al actor de quien puede prever. Además, se ignora que la causalidad en el sentido habitual incluye mucho más que la previsibilidad. Usualmente también se exige la posibilidad de controlar el curso de los acontecimientos, aunque esto sea todavía insuficiente. El relato de la confusión de paraguas nuevamente demuestra que poder prever y controlar un resultado no convierte la acción de quien se encuentra en esa posición en causa. ¿Qué más se requiere? Esta no es una pregunta que pretenda responder aquí. Sólo diré que algunos han intentado analizar la cuestión a partir de casos paradigmáticos. Para RosenKRANTZ, por ejemplo, la combinación de previsibilidad, control y expectativas sociales de un determinado comportamiento individual hace que alguien pueda ser considerado causante en los supuestos causales paradigmáticos. En los casos no paradigmáticos no se requiere necesariamente ninguno de estos elementos, sino que el caso cuadre dentro de algún otro paradigma de causación ${ }^{66}$. Pese a lo complejo de estas teorías y las dificultades teóricas a las que nos enfrentan, lo que es indudable es que capturan en gran medida nuestras intuiciones al momento de realizar juicios causales. Todo el mundo aceptaría que Álvaro no es el causante de la confusión y la pérdida del paraguas de Mateo, pese a haber tenido previsibilidad y control sobre la situación. El caso no es una instancia paradigmática de causación justamente porque no había ninguna expectativa social de que Allvaro interviniese en los acontecimientos.

66 Rosenkrantz, 2005, pp. 22-23. 
En conclusión, el AED debe reconocer que no puede dar cuenta de la exigencia de causalidad, porque muchas veces requerirla conduce a resultados ineficientes. CALABRESI indirectamente reconoce que ello es así cuando afirma que ningún concepto causal por sí mismo puede satisfacer todas las metas del sistema de responsabilidad extracontractual. No obstante, intenta interpretar los conceptos causales a la luz de la eficiencia y para poder hacerlo abandona las caracterizaciones usuales de los juristas, de modo que incumple su objetivo inicial: dar cuenta del requisito de causalidad.

\subsubsection{Un último intento de explicación económica}

A partir del trabajo de CALABRESI, S. SHAVELl desarrolló un interesante modelo económico para explicar por qué el Derecho de daños limita el ámbito de la responsabilidad a las acciones causadas por el agente dañador. En otras palabras, su modelo intenta explicar por qué es eficiente que los individuos sean responsables sólo por los daños que causan ${ }^{67}$.

Veamos uno de los varios ejemplos que SHAvelL analiza en su trabajo ${ }^{68}$ : si un ciclista entra al parque puede verse involucrado en un accidente con un corredor, que a su vez podría sufrir un daño en toda circunstancia (supongamos que si no es atropellado por el ciclista tropezará con una rama que le ocasionará exactamente la misma lesión) ${ }^{69}$. La situación está ilustrada en la tabla que sigue:

\begin{tabular}{|l|c|c|c|}
\hline \multirow{2}{*}{ Acciones } & \multicolumn{3}{c|}{ Estados } \\
\cline { 2 - 4 } & $\begin{array}{c}\text { Poca } \\
\text { visibilidad }\end{array}$ & $\begin{array}{c}\text { Visibilidad } \\
\text { moderada }\end{array}$ & $\begin{array}{c}\text { Buena } \\
\text { visibilidad }\end{array}$ \\
\hline Probabilidad & 0,01 & 0,02 & 0,097 \\
\hline $\begin{array}{l}\text { El ciclista entra al parque pero } \\
\text { no es diligente }\end{array}$ & Pérdida de 200 & Pérdida de 100 & No hay pérdida \\
\hline $\begin{array}{l}\text { El ciclista entra al parque y es } \\
\text { diligente }\end{array}$ & Pérdida de 200 & No hay pérdida & No hay pérdida \\
\hline El ciclista no entra al parque & Pérdida de 200 & No hay pérdida & No hay pérdida \\
\hline
\end{tabular}

Nota: el coste de la precaución es de uno y el beneficio que obtiene el ciclista al entrar al parque es de 2,5.

El valor esperado de cada una de las acciones es el siguiente:

a) El ciclista entra al parque y no es diligente: $2,5-(0,01) \cdot(200)-(0,02) \cdot(100)$ $=-1,5$.

b) El ciclista entra al parque y es diligente: $2,5-1-(0,01) \cdot(200)=-0,5$.

c) El ciclista no entra al parque: $-(0,01) \cdot(200)=-2$.

67 SHAVELL, 1980.

68 SHAVELL, 1980, pp. 472-473.

69 Los supuestos poco realistas empleados por SHAVELL son duramente criticados en WRIGHT, 1985, pp. 444-445. 
El resultado eficiente es que el ciclista entre al parque y sea diligente. Sin embargo, si es responsabilizado objetivamente por el accidente en los tres estados del mundo posibles el ciclista se abstendrá de entrar al parque. Por esta razón, el requisito de la relación causal tiene por función excluir del ámbito de responsabilidad el estado donde hay poca visibilidad. Dado que la diligencia del ciclista es indiferente para la producción del daño, no tiene sentido responsabilizarlo. La responsabilidad haría que el nivel de actividad del ciclista se reduzca ineficientemente. Si la regla es de negligencia, en cambio, la reducción del ámbito de responsabilidad no surte ningún efecto sobre sus incentivos. Como siempre, con esta regla tendrá incentivos para tomar las medidas óptimas, de modo que la concreción de otros estados del mundo será indiferente para el ciclista.

Este es a grandes rasgos el argumento de SHAVELL. Sin duda presenta un avance respecto del estado anterior de la cuestión. Es un intento interesante por explicar por qué la ausencia de relación causal es eximente de responsabilidad. Pese a ello, creo que el modelo sigue siendo deficiente porque confunde la causalidad con la negligencia. Obsérvese que económicamente lo que él denomina ausencia de causalidad no es más que otro caso en el que las medidas precautorias óptimas por parte del agente dañador son 0. En este esquema no es posible identificar una conducta como la causa de un resultado dañoso, sin calificarla como negligente a la vez. Para ser causante el agente debió poder alterar el resultado dañoso de alguna manera. Los modos de alterarlo son dos: tomando medidas precautorias o reduciendo el nivel de actividad. En el cuadro ninguna de estas dos alternativas disminuye el daño de 200 cuando hay poca visibilidad. Ello indicaría, según SHAVELL, que hay ausencia de causalidad, por lo que ese estado debe ser excluido del ámbito de la responsabilidad.

Sin embargo, si fuese posible reducir el daño tomando medidas eficientes, el agente no sólo sería considerado causante sino además negligente ${ }^{70}$. Asimismo, en todos los casos en que el agente se comporta diligentemente, es decir, cuando ya agotó las medidas óptimas que podía tomar, como marginalmente la diligencia debida es 0 , habrá que afirmar que a partir de ese punto no sólo deja de ser negligente sino también que deja de ser causante si el daño se produce. Ello es así porque la causalidad se define a partir de la posibilidad de reducir el daño tomando medidas óptimas (lo que en términos económicos debería incluir el nivel de actividad, como se vio en la Sección III).

En la misma línea, es posible que una reducción en el nivel de actividad sea ineficiente y que además no haya medidas precautorias óptimas que el agente pueda tomar. En este caso, aun cuando nuestro lenguaje ordinario identificase al agente como causante, el análisis de SHAVELL debería afirmar lo contrario. Con la explicación que ofrece en su trabajo resulta imposible distinguir la causa de la negligencia; y entonces, mal puede dar cuenta del requisito de causalidad en el Derecho de daños.

${ }^{70}$ Queda descartado como criterio para distinguir la culpa de la causalidad la posibilidad de adoptar medidas que, aunque sean ineficientes, reduzcan el daño esperado. Así, la causalidad sería la posibilidad de reducir el daño con cualquier tipo de medidas, ya sean eficientes o ineficientes, y la culpa la posibilidad de reducir el daño sólo con medidas eficientes. Este argumento no funciona porque quien adopta medidas ineficientes para reducir el daño en realidad empeora la situación dado que incrementa el coste total del accidente. Debe recordarse que el coste del accidente incluye, entre otras cosas, el valor del daño y de las medidas precautorias. Una noción de causalidad como la aquí intentada carecería de sentido económico. ¿Cuál es la ventaja de identificar como causa a quien de ningún modo puede reducir el coste del accidente? 
De la misma opinión son LANDES y POSNER. Ellos sostienen que acudir a conceptos causales es innecesario para analizar los casos de responsabilidad extracontractual. Explícitamente reconocen que «la violación de un estándar no es negligencia o, si uno desea usar la palabra, no es la causa de un accidente» cuando los costes esperados no disminuyen con un nivel mayor de medidas precautorias (la cursiva me pertenece) ${ }^{71}$. Desde un punto de vista funcional, debe considerarse causante al agente que, según el estándar de eficiencia, deba ser responsabilizado a fin de brindarle los incentivos para que adopte las medidas precautorias óptimas que minimizarán el coste de los accidentes. Para estos autores, carece de sentido afirmar que un individuo causó un daño pero no debe ser responsabilizado ${ }^{72}$.

La confusión entre causalidad y negligencia también es explícita en los modelos formales. Así, R. COOTER explica que la causalidad en el Derecho de daños es concebida en términos de relaciones funcionales entre tres variables: la probabilidad de que ocurra el accidente, el daño que causa y las medidas precautorias que pueden adoptarse para prevenirlo ${ }^{73}$. Estas tres variables, debe recordarse, son las mismas que la famosa fórmula del juez Learned Hand considera relevantes para definir la negligencia. Una vez más queda claro que, en la interpretación económica, el ámbito de la causalidad coincide exactamente con el ámbito de la negligencia. Ello es así porque ambos conceptos constituyen un juicio de eficiencia ${ }^{74}$.

En conclusión, ninguna de las explicaciones económicas de la causa resulta convincente como descripción del modo en que este requisito opera en el Derecho de daños. Algunos modelos como el de SHAVELL se acercan más que otros que, como el de LANDES y POSNER, directamente niegan la relevancia de la causalidad en el Derecho, pero siguen siendo por razones conceptuales insuficientes para dar cuenta del uso de estos conceptos por parte de los juristas.

\subsection{La obligación de reparar y el derecho a ser compensado}

En el punto II expliqué que para el AED la obligación de pagar por los daños que causamos encuentra su justificación en los incentivos que el agente dañador tiene para tomar medidas precautorias. Siempre que deba reparar los daños que son consecuencia de sus acciones obrará con la diligencia debida, lo que minimizará el coste de los accidentes.

Desde el punto de vista de la víctima, son dos las razones por las que debe recibir compensación. Por una parte, el hecho de que pueda reclamar al agente dañador una reparación hace que los incentivos de este último sean operativos. La obligación de compensar por sí misma es insuficiente para motivar adecuadamente al victimario. Entonces, el derecho a ser reparado es un incentivo para que la víctima reclame al agente, lo que a su vez funciona como incentivo para que éste adopte medidas precautorias. Paralelamente, el derecho de la víctima a recibir una compensación se explica porque es una forma de impedir que ella realice inversiones excesivas en medidas de

\footnotetext{
71 LANDES y POSNER, 1983, p. 113.

72 LANDES y POSNER, 1983, p. 110.

73 CoOter, 1987, pp. 523 y 540.

74 CoOter, 1987, p. 540.
} 
autoprotección. Si no hubiese un derecho a ser reparado la autoprotección superaría los niveles eficientes, aunque nunca el valor del daño.

La obligación de compensar y el derecho a ser reparado, de este modo, pueden ser explicados a partir del principio de eficiencia. Sin embargo, señala WEINRIB, el AED no brinda ninguna razón para tomar del agente dañador la misma suma que se le otorga a la víctima, ni para fijar el monto indemnizatorio en el valor del daño. Por tanto, no puede dar cuenta de la característica más sobresaliente de la responsabilidad extracontractual $^{75}$. En otras palabras, lo que el AED no puede explicar es por qué el valor del daño es la referencia para establecer el monto que debe pagar el agente dañador y que debe recibir la víctima.

La primera parte del argumento de WEINRIB consiste en pensar qué suma de dinero es suficiente para incentivar correctamente al agente dañador. Supongamos que un daño de 1.000, que tiene una probabilidad de ocurrencia del 25 por 100, puede ser evitado a un coste de 100 en medidas precautorias. Una indemnización que, valorada ex ante, sea superior a 100 brindará los incentivos adecuados al agente para que adopte las medidas. ¿Qué suma es ex ante superior a 100 cuando la probabilidad de ser responsabilizado es del 25 por 100? La respuesta es cualquier suma superior a 400. Piénsese que, si hay un 25 por 100 de probabilidades de ser encontrado responsable y el valor de la indemnización en ese caso es mayor que 400, esto brindará incentivos suficientes para invertir 100 en medidas precautorias. Claro que obligar a compensar por 1.000 también provee los incentivos correctos, porque 1.000 es superior a 400, pero no hay ninguna ventaja comparativa, en cuanto a los incentivos del agente dañador para tomar medidas precautorias, en obligarle a pagar 1.000 antes que cualquier suma inferior a ésta pero mayor que 400. En definitiva, el AED no puede explicar por qué el agente dañador debe ser obligado a pagar el valor del daño y no una suma que sea simplemente suficiente para brindarle los incentivos correctos en cuanto a la adopción de las medidas precautorias ${ }^{76}$.

La segunda parte del argumento tiene que ver con los incentivos que afectan a la víctima. WeINRIB sostiene que la suma de dinero necesaria para motivarla a que demande al agente dañador no se corresponde indefectiblemente con el valor de daño sufrido. La comparación entre la situación de la víctima luego del daño y la situación en la que se encontraría de no haber tenido lugar el accidente es irrelevante para determinar el monto indemnizatorio. Una vez acaecido el daño, la comparación relevante es la que se realiza entre la situación de la víctima si demanda y su situación si no demanda. Cualquier suma de dinero que mejore la situación de la víctima una vez ocurrido el accidente será suficiente para incentivarla a demandar. Incluso, descontados los costes de reclamar judicialmente, una suma fija que sea independiente del valor del daño será suficiente para brindar este tipo de incentivos.

Si se reconoce esto, entonces, el escenario es aún peor para el AED, ya que no puede explicar por qué sólo la víctima puede reclamar al agente dañador y no cualquier otra persona ${ }^{77}$. Dado que la indemnización mejora la situación de cualquiera que la

\footnotetext{
75 WEINRIB, 1989, p. 506

76 WEINRIB, 1989, p. 507.

77 WEINRIB, 1989, p. 508
} 
reclame, para hacer operativos los incentivos del agente dañador no es necesario limitar el número de posibles reclamantes. Obviamente, si nos interesase también lograr el objetivo compensación, debería asignarse una prioridad a la víctima para evitar superposiciones, lo que haría que el monto demandado sea superior al monto necesario para incentivar al agente dañador a adoptar medidas precautorias óptimas.

En relación con esto, la segunda razón que esgrime el AED para conceder una indemnización a la víctima, y no a cualquier otra persona, es evitar un exceso de autoprotección. Si no hubiese compensación, las potenciales víctimas adoptarían medidas precautorias aun cuando ello fuese ineficiente (supongamos, porque el agente dañador, o un tercero, pueden evitar el daño de modo más económico). Sin embargo, este argumento funciona siempre que el coste de las medidas de evitación que la víctima tenga a su disposición sean menores que el coste esperado del daño. Cuando el coste de las medidas sea superior, la víctima no tendrá incentivos a adoptarlas — ya que preferirá soportar el daño- - por lo que no hay peligro de que se exceda en la autoprotección. Así, pese a que no es necesario evitar una inversión excesiva en medidas precautorias por parte de la víctima, el Derecho de daños establece una indemnización de todos modos.

En realidad, la situación es todavía más grave, porque la crítica puede extenderse a los casos en los que el coste de las medidas precautorias es inferior al valor del daño. Supongamos que la víctima puede evitar un daño de 1.000 a un coste de 200 y el agente dañador puede hacerlo a un coste de 100. Otorgar indemnización a la víctima es una forma de evitar que invierta 200 en precaución, ya que lo eficiente es que el agente dañador invierta 100; justamente, para lograr esto último se lo responsabiliza por daños. No obstante, a fin de evitar que la víctima tome medidas en este caso, no es necesario que se le conceda una indemnización igual al valor del daño. En nuestro ejemplo, como la probabilidad de ocurrencia del accidente es del $25 \%$, otorgar una indemnización inferior a 200 será incentivo suficiente para que no invierta los 200 en medidas. Supongamos que se otorga una indemnización de 201. En ese caso, si ocurre el accidente la víctima sufrirá una pérdida de 799 (1000 del daño menos 201 de la indemnización). El valor esperado de la pérdida es de 199, 75 (799 x 25\% de probabilidades). Por ello, sería irracional que la víctima invierta 200 en precauciones para evitar sufrir una pérdida de 199, $75^{78}$.

Si estas críticas son correctas, los partidarios del AED tienen un problema para explicar el modo en que están vinculados el agente dañador y la víctima en la responsabilidad extracontractual. Pese a todo, el economista podría responder que la bilateralidad se explica porque es la manera en que la comunidad logra una disuasión óptima. Es cierto que para alcanzar este objetivo no es necesario que el agente dañador compense a la víctima, sino que pague una suma de dinero a alguien. $\mathrm{Ni}$ siquiera es necesario que intervenga el Derecho de daños. Esta meta podría lograrse por medio del Derecho penal, imponiendo desde multas hasta penas privativas de la libertad. El economista responderá entonces que la vinculación por medio de la compensación es una de las muchas herramientas útiles para lograr una disuasión eficiente. Lo que no podrá explicar es por qué en ciertos contextos en los que no es un medio eficiente de todos modos el Derecho de daños otorga a la víctima un derecho

78 Esta es la idea del argumento de WEINRIB, 1989, p. 509, aunque su cálculo es diferente. 
a recibir compensación correlacionado con la obligación a cargo del agente dañador. Veamos la cuestión.

Hay ocasiones en las que otorgar un derecho a demandar compensación produce resultados ineficientes. Esas ocasiones son aquellas en las que el derecho a reclamar no incentiva al agente dañador a adoptar medidas precautorias para disminuir el valor esperado del daño. Nótese que si se niega la posibilidad de demandar el coste social esperado estará dado por el valor del daño ponderado por la probabilidad de su ocurrencia $[D . p(x)]$, teniendo en cuenta que el agente dañador no adoptará medidas precautorias eficientes $\left(x<x^{*}\right)$. Otorgar un derecho a la víctima se justifica sólo si la suma de los costes esperados de litigio para el actor $\left(L_{A}\right)$, para el demandado $\left(L_{D}\right)$ y para el Estado $\left(L_{E}\right)$ son menores que lo que se gana por la reducción del daño cuando el agente dañador adopta medidas precautorias. En símbolos, si $D \cdot p(x)-D \cdot p\left(x^{*}\right)-x^{*}>\left(L_{A}\right.$ $\left.+L_{D}+L_{E}\right) \cdot p\left(x^{*}\right)$ entonces es eficiente otorgar derecho a la víctima. Si la relación es inversa, es ineficiente y el Estado debería negar el derecho a demandar ${ }^{79}$. Otro modo de explicarlo es el siguiente. En aquellos casos en los que el derecho a demandar no incentiva al agente a tomar medidas precautorias, si se otorga el derecho el coste social esperado es $\left(D+L_{A}+L_{D}+L_{E}\right) \cdot p(x)$, pero si se niega el derecho el coste esperado es $D \cdot p(x)$, una suma necesariamente menor porque no incluye los costes de litigio ${ }^{80}$.

¿Cómo justificaría un partidario del AED el derecho de la víctima en estos casos? Diría que el Estado no puede identificar a un coste razonable qué demandas son eficientes y cuáles no lo son. Esto exigiría determinar cómo impacta el derecho a demandar de la víctima sobre los incentivos del agente dañador para tomar medidas precautorias. Nuevamente, el AED encuentra una justificación ad hoc para lo que no tiene explicación. El lenguaje del Derecho de daños considera que el derecho de las víctimas es un componente central de la práctica con independencia de que sirva a la disuasión de los agentes dañadores. El derecho de las víctimas no es simplemente uno de los modos eficientes que tiene el derecho para incentivar al agente dañador. De hecho, los sistemas complementan la disuasión con multas administrativas, multas penales o penas privativas de la libertad, pero rara vez excluyen el derecho de la víctima a reclamar por daños. Este derecho a la compensación cuenta en la práctica con una justificación autónoma; no depende en ningún sistema jurídico occidental de que sirva a la consecución de algún objetivo social como la disuasión del agente dañador.

Considérese el caso de los daños de baja cuantía que las empresas causan a los consumidores. Ningún consumidor tendrá incentivos para reclamar, porque usualmente el coste de litigar es mayor que el monto indemnizatorio. Esta circunstancia hace que las empresas no adopten medidas precautorias a fin de evitar esos daños. Supongamos que es eficiente que la empresa invierta en mejorar la calidad de su producto para evitar el perjuicio a los consumidores. El Estado reconoce que, pese a que el coste de las medidas precautorias de la empresa es menor que el valor agregado del daño que sufren los consumidores, si todos los consumidores iniciasen procesos judiciales - no

79 Los incentivos de la víctima para demandar no dependen de los costes y los beneficios sociales sino de que su coste de demandar sea menor que la indemnización que recibirá si gana el pleito. Por ello, la víctima iniciará un proceso judicial cada vez que obtenga un beneficio privado de ello con independencia de que su demanda sea socialmente beneficiosa.

80 Vid. SHAVELL, 2007, pp. 151-153. 
para recibir una compensación monetaria, que será menor que el coste de litigar, sino por la satisfacción que supone haber ganado el juicio a la empresa- el resultado sería ineficiente ${ }^{81}$. Sin embargo, en estos casos el Estado suele otorgar de todas maneras un derecho a reclamar, aunque no hace depender la disuasión, que es un objetivo válido de todo sistema, de la acción de la víctima. Para lograrla se vale, en cambio, de otras medidas como los controles administrativos y las multas. De ninguna manera los instrumentos empleados para la disuasión interfieren con el derecho de la víctima. Esto es así porque la justificación de este derecho es independiente de la eficiencia.

Estos argumentos demuestran que la explicación que ofrece el AED es inconsistente y no captura un rasgo importante de la responsabilidad extracontractual. Todos los argumentos esgrimidos por los partidarios de esta corriente - el de la generación de incentivos para que el agente se comporte diligentemente, el de la motivación de la víctima para que reclame, lo que en última instancia hace operativos los incentivos del victimario, el argumento de la autorprotección, etc.—, son falaces. La explicación del AED sobre la vinculación del agente dañador y la víctima deja al descubierto que para esta teoría la única relación que existe se da entre el agente dañador y la víctima, individualmente, con los objetivos de la responsabilidad extracontractual ${ }^{82}$. No hay una razón económica que explique el vínculo entre ellos sino que cada uno está conectado independientemente con las metas del sistema de reparación de daños. El mayor problema es que el AED no toma en serio la estructura bilateral, y esto resulta fundamental si se pretende captar la racionalidad subyacente de la responsabilidad extracontractual.

\section{MÁS ALLÁ DEL ANÁLISIS CONCEPTUAL}

En la sección precedente intenté mostrar que el AED es incapaz de ofrecer una explicación conceptual de la responsabilidad extracontractual. Quienes encuentren que este argumento es persuasivo, aun deberán enfrentarse a la posible objeción que mencioné en la introducción. La cuestión era la siguiente: los críticos del AED sostienen que la eficiencia no permite dar cuenta de la estructura conceptual del Derecho de daños. Sin embargo, tal vez el AED no pueda dar cuenta de ella porque una buena explicación no se limita necesariamente a las categorías tradicionales. La verdadera explicación de la práctica tiene poco que ver con las razones que expresamente invocan los jueces para fundamentar sus decisiones. Limitarse al estudio de ese discurso es quedarse con lo más superficial de las prácticas. Planteada de este modo, la objeción

81 Supongamos que la empresa genera a 100 consumidores un daño de uno a cada uno. También, que puede evitar ese daño agregado de 100 invirtiendo diez en medidas precautorias. Por otra parte, imaginemos el coste de demandar para cada consumidor es de dos. Asimismo, digamos que el coste de cada litigio para el empresario es de dos y para el Estado de 1,5. Con estos valores se dará que: a) los consumidores no demandarán por daños en general, ya que obtendrán uno de indemnización pero el coste de litigar es de dos (algunos podrán demandar por la satisfacción psicológica de ganar el pleito a la empresa); b) la empresa no adoptará medidas precautorias que son eficientes porque sabe que no será demandada, y $c$ ) conceder un derecho a las víctimas es ineficiente porque el daño agregado es de 100 y puede ser evitado invirtiendo diez. Por tanto, lo que hay para ganar es 90 cuando el agente adopta las medidas óptimas. ¿Cuál es el coste de reducir daños por 90? Debemos sumar el coste de litigar para todos los involucrados. Así, el valor de los litigios será de 550 (200 para los consumidores, 200 para la empresa y 150 para el Estado).

82 Coleman, 1988, p. 1250. 
sugiere que el análisis de los conceptos fundamentales, como la culpa o la causalidad, no es lo único relevante al estudiar el Derecho de daños. En otras palabras, la objeción sugiere que puede haber una genuina explicación o comprensión de la responsabilidad extracontractual aun cuando no se logre dar cuenta de las nociones centrales que organizan la práctica.

Esta objeción tiene dos problemas. Para advertirlos debe hacerse referencia a una distinción clásica entre las explicaciones externas y las explicaciones internas. Las primeras, inspiradas en el método de las ciencias naturales, apuntan a la medición de datos, la predicción, la atribución de funciones o a la comprobación empírica. Las explicaciones internas, en cambio, dan cuenta del fenómeno analizando el esquema conceptual de los participantes. Fue H. HART quien señaló con mayor contundencia la necesidad de tomar en consideración el punto de vista interno para hacer inteligibles las prácticas jurídicas ${ }^{83}$. En este segundo tipo de explicación, a diferencia de las explicaciones externas, lo relevante es la autocomprensión que los propios participantes tengan de la realidad social que se esté estudiando. La idea subyacente es que los hombres pueden ser comprendidos de un modo en que las hormigas no pueden serlo. Los hombres obran por razones y, hasta donde sabemos, esta es una diferencia fundamental que debemos reconocer respecto del estudio de otros fenómenos del mundo, como el comportamiento de los animales o el desplazamiento de las placas tectónicas. Estudiar el movimiento de las placas, comprender por qué tiene lugar y lograr predecir futuros movimientos, no exige indagar en el esquema conceptual de nadie. La comprensión es desde el punto de vista externo, y está más asociada con las causas que con las razones. Por su parte, la comprensión de una práctica requiere, como mínimo, determinar que se está frente a una práctica y no frente a un hábito social o una mera conducta convergente. Por ejemplo, si nos situamos en una esquina y observamos a los ciudadanos de nuestra ciudad, veremos que la mayoría detiene la marcha de su automóvil cuando el semáforo cambia a rojo. También veremos que la mayoría de las personas sale a la calle con paraguas cuando llueve. Sabemos, de todos modos, que frenar en el semáforo rojo es obligatorio y que no mojarse no lo es. Lo primero está determinado por una práctica normativa y lo segundo solo constituye una conducta convergente. Todo esto lo sabemos porque tomamos en cuenta las creencias y actitudes de los participantes. Nótese que si limitásemos nuestro análisis a la conducta externamente observable, frenar en el semáforo rojo y salir a la calle con paraguas cuando llueve solo serían regularidades fácticas. Interpretar la primera regularidad como el seguimiento de una regla y la segunda como una conducta meramente generalizada supone considerar el significado que el semáforo rojo y la lluvia tienen para los participantes. Cómo ellos entienden las reglas es determinante para distinguir lo que consideran obligatorio y lo que consideran recomendable hacer en muchas ocasiones. Así, quienes no desean mojarse juzgan recomendable salir con paraguas a la calle cuando llueve, mientras que cuando se trata de frenar en el semáforo rojo, no lo juzgan recomendable sino obligatorio; lo entienden como un estándar legítimo de conducta cuyo incumplimiento justifica la crítica.

No voy a iniciar aquí un análisis de las prácticas normativas. Mi intención es mostrar que este tipo de conclusiones, que a primera vista parecen correctas, solo son po-

83 Hart, 1994, p. 80. 
sibles si se toma en cuenta el punto de vista interno, cuyo análisis requerirá determinar el contenido de los conceptos que los individuos emplean para desenvolverse en la realidad social y, además, explicitar el modo en que estas nociones están relacionadas entre sí y con el conjunto de inferencias que se realizan normalmente en la comunidad en cuestión. Una vez hecha esta distinción entre explicaciones internas y explicaciones externas, es fácil advertir que el AED no puede desentenderse de los conceptos que organizan la práctica y pretender de todas formas brindar una explicación interna. Si bien es cierto que el AED critica la interpretación tradicional de los conceptos y las categorías centrales del Derecho de daños, y por ello intenta recaracterizarlos de conformidad con el principio de eficiencia, sus explicaciones no se convierten automáticamente en externas. J. KRAUS, en un excelente trabajo, realiza un esfuerzo argumentativo importante para mostrar que el AED puede satisfacer el punto de vista interno ${ }^{84}$. Considero que los argumentos expuestos en el apartado IV son suficientes para descartar intentos como el de KRAUS ${ }^{85}$.

Ahora bien, ¿podría el AED recomendar el abandono del punto de vista interno? Es decir, si el punto de vista interno se limita a lo superficial de las prácticas, al análisis de un discurso que puede estar viciado por mitos y supersticiones, ¿por qué no adoptar una metodología externa? De hecho, un tipo muy difundido de explicación externa es la explicación funcional. Esta consiste en identificar qué beneficios producen las instituciones para las comunidades que las sustentan ${ }^{86}$. El AED fácilmente podría convencernos de que el Derecho de daños bilateral reduce la cantidad y la gravedad de los accidentes respecto de un esquema alternativo en el cual el causante del daño no tiene la obligación de repararlo. Dados los incentivos perversos que generaría un sistema con estas características, es plausible afirmar que si el Derecho de daños bilateral no existiese el coste total de los accidentes sería mucho más elevado. Una de las ventajas de las explicaciones externas — podría seguir el argumento- es que el teórico no se encuentra limitado al análisis de un discurso, sino que se enfrenta a una hipótesis comprobable empíricamente mediante la comparación de datos.

Esta propuesta parece razonable. En efecto, si una teoría es superior a otra debemos adoptarla dejando de lado las ideas de la teoría anterior. Pero el AED requiere mucho más que esto. Requiere que abandonemos una metodología completa, no una teoría. Abandonar el punto de vista interno al estudiar el Derecho de daños implica desprendernos de ciertas categorías profundamente enraizadas en nuestro modo de ver el mundo. Para encontrar sentido a la responsabilidad extracontractual necesitamos la distinción entre la acción incorrecta y la acción que sin ser incorrecta genera riesgos; necesitamos establecer un concepto de causalidad, relacionarlo con una teoría general de la responsabilidad y con los principios fundamentales de la moralidad en que estas nociones se asientan. Entendemos nuestras relaciones sociales sirviéndonos de estos conceptos. Y, a diferencia de lo que supone la crítica a las explicaciones internas, estudiar las ideas con las que comprendemos el mundo es una tarea filosófica

84 KraUs, 2007, p. 299.

85 Corresponde aclarar que el trabajo de KRAUS tiene por objeto responder al tipo de críticas que formulo en la sección IV. Creo que sus argumentos no son convincentes, pero por razones de espacio no puedo detenerme aquí a discutirlos.

86 DurKHEIM, 1895, p. 140. 
de gran importancia. En estas ocasiones reflexionamos sobre las razones por las que actuamos de determinada manera y logramos entendernos con mayor profundidad.

Creo que ambos tipos de explicación pueden contribuir a nuestra comprensión de un fenómeno jurídico, pero de distinta manera. Las explicaciones internas contribuyen en la medida en que logramos por medio de ellas un conocimiento teórico de aquello que nos es cotidiano. Las explicaciones externas, por su parte, nos permiten conocer los efectos positivos o negativos de las instituciones con las que organizamos la vida en sociedad. Si el teórico desea saber, por ejemplo, qué incentivos reciben el agente dañador y la víctima cuando entra en vigor una regla de responsabilidad objetiva por accidentes de tránsito, o cuál es el impacto distributivo de una regla que establece la responsabilidad solidaria de toda la cadena de producción por los defectos de fabricación del producto o por la prestación defectuosa de un servicio, entre otras muchas cuestiones que podrían investigarse, la metodología externa es la más adecuada. Esto es así porque en ningún caso es necesario indagar en el esquema conceptual de los participantes para responder a estas preguntas.

Dado que ambas metodologías ofrecen cosas distintas, es ilegítimo privilegiar a una sobre la otra. El hecho de que el AED sea incapaz de brindar una explicación interna de la responsabilidad extracontractual no debe llevar a los teóricos a postular que las explicaciones externas son las únicas «científicas» o a negar el valor del análisis conceptual ${ }^{87}$. La comprensión del Derecho siempre es parcial, y las teorías que se producen en cada tradición metodológica son inconmensurables. Por otra parte, es absurdo pretender una comprensión de todos los aspectos de la práctica apelando a una sola metodología. Por ello, el debate entre el AED y los partidarios de teorías alternativas, entre las que se encuentra la justicia correctiva ${ }^{88}$, debe desarrollarse teniendo en cuenta que muchas veces los primeros pretenden brindar explicaciones externas, mientras que los segundos siempre ofrecen una explicación interna. Así las cosas, el debate puede resultar inútil. Dicho en otros términos, si el AED pretende explicar los efectos positivos de la responsabilidad extracontractual bilateral sobre la cantidad y la gravedad de los accidentes, y los partidarios de la justicia correctiva pretenden explicar la comprensión que tienen los propios participantes de la práctica del Derecho de daños, parece que no están discutiendo sobre lo mismo. Ahora, cuando el AED se propone ofrecer una explicación interna existe una base de acuerdo suficiente como para que el desacuerdo con los teóricos de la justicia correctiva tenga sentido. De todas maneras, en el desarrollo precedente intenté mostrar que, cuando este es el caso, el AED ofrece una teoría poco satisfactoria.

87 POSNER sostiene que la teoría tradicional está viciada de inicio porque se vale de clasificaciones como la distinción entre el Derecho civil y el Derecho penal o, dentro del Derecho civil, entre la responsabilidad contractual y la extracontractual; estas conceptualizaciones, según POSNER, son propias de un pensamiento esencialista que se preocupa inútilmente por definir la palabra «derecho». Lo mismo corresponde afirmar respecto de la asociación del Derecho penal con la disuasión y del Derecho de daños con la compensación. En lugar de pensar en el Derecho penal o el Derecho civil como conceptos se los debe concebir como instrumentos. En términos de su función, el Derecho civil y el Derecho penal ponen un «precio» a las conductas para desalentarlas o, al menos, controlarlas. Vid. POSNER, 1996, p. 54.

88 Para los partidarios de la justicia correctiva, la base de la responsabilidad civil se encuentra en los principios que ordenan la compensación de daños como respuesta racional a la comisión de una acción incorrecta. Vid. WeINRIB, 1995. Para una visión distinta de la justicia correctiva, COLEMAN, 1992. 


\section{CONCLUSIONES: EL LUGAR DEL AED EN EL DERECHO DE DAÑOS}

En el desarrollo precedente sostuve que el AED no puede ofrecer una explicación conceptual de la práctica que tenga en cuenta el punto de vista interno. Ello es así porque los conceptos fundamentales que organizan el Derecho de daños son reconstruidos de un modo irreconocible para cualquier participante de la práctica. El análisis, por supuesto, no debe limitarse a reproducir los rasgos más obvios del fenómeno, aunque debe preservarlos de alguna manera. Probablemente si preguntásemos a los jueces que deciden los litigios de responsabilidad extracontractual cuánto saben acerca de la justicia correctiva, en la mayoría de los casos nos encontraremos con respuestas muy poco precisas. No obstante, es plausible sostener que la justicia correctiva es una explicación interna del Derecho de daños. Ello es así porque aunque los jueces no sean conscientes de ello en su labor cotidiana, luego de una adecuada reflexión, reconocerían que el Derecho de daños es una implementación de la justicia correctiva. En cambio, nunca reconocerían a la eficiencia como el principio que aplican al decidir un caso de responsabilidad civil. En la sección IV intenté elaborar un argumento para justificar esta afirmación. Sintetizando lo que tienen en común todas las críticas allí presentadas, puede decirse que la eficiencia distorsiona aquellos rasgos del Derecho de daños que nos resultan familiares: $a$ ) el tipo de razonamiento que se expresa en las sentencias para justificar un juicio de responsabilidad por daños; $b$ ) la distinción entre las conductas riesgosas permitidas y las conductas prohibidas, conceptos que subyacen a la responsabilidad objetiva y la culpa, las dos reglas fundamentales del Derecho de daños; c) la importancia de la relación causal, y $d$ ) la vinculación particular que se produce entre el agente dañador y la víctima luego del acaecimiento de un daño en ciertas condiciones.

Una vez desarticulados los conceptos que se emplean en la práctica también quedan desarticuladas las inferencias que normalmente se realizan para llegar a una adscripción de responsabilidad. De esta manera, sin la noción de causalidad es incomprensible la vinculación entre la víctima y el agente dañador. ¿Por qué no podría la víctima demandar a quien puede pagar el daño, en lugar de demandar a quien lo causó? Las razones que justifican rechazar ciertas demandas y condenar al pago de una indemnización en otras tienen que ver con este entramado conceptual. El principio de eficiencia disuelve estas categorías y, con ellas, también disuelve el razonamiento práctico de los participantes de la práctica. Siendo ello así, el AED no puede satisfacer las características de una explicación interna.

No obstante, el AED puede ofrecer un tipo de explicación distinto. Me refiero a la explicación funcional, que es externa porque el modo en que los participantes interpretan el Derecho de daños es irrelevante para esta aproximación. Las explicaciones funcionales daban un marco teórico a los estudios predictivos, aquellos que buscan medir los efectos de las distintas reglas de responsabilidad sobre los incentivos de los agentes y la asignación final de los recursos. Esta tarea tiene un gran valor, y debe reconocerse que la mayoría de los analistas actualmente realizan este tipo de estudios ${ }^{89}$.

89 COOTER, entre otros, admite que la idea de reducir las categorías y los conceptos tradicionales a un análisis coste-beneficio es absurda. También afirma que la posibilidad de dar cuenta de la coherencia de los sistemas jurídicos a la luz de la eficiencia depende de qué área del Derecho se esté analizando, pero en general el 
Por último, es importante aclarar que ninguno de estos enfoques es superior al otro. Las explicaciones internas iluminarán algunos aspectos de la práctica que no pueden ser iluminados por las explicaciones externas, y viceversa. De todas formas, debe advertirse que al trazar esta distinción no estoy identificando inexorablemente al AED con las teorías externas. El AED puede ofrecer explicaciones también internas, aunque resulta ser una mala explicación de la responsabilidad extracontractual. Sin embargo, que fracase como explicación interna del Derecho de daños no significa que fracase como explicación interna de todas las ramas del Derecho. Acertadamente, en mi opinión, POSNER reconoce que «los límites de la economía no pueden ser determinados de antemano (...). Eventualmente se llegará a un punto en el que la teoría económica deje de tener un poder explicativo sustancial» ${ }^{90}$. Considérese la normativa de defensa de la competencia. Claramente estas reglas pueden ser interpretadas como una implementación del principio de eficiencia. Las inferencias prácticas que se realizan en este ámbito, el discurso de los funcionarios públicos que controlan las fusiones y adquisiciones o que, entre otras cosas, investigan la celebración de acuerdos colusorios, y el discurso de las empresas que participan en el mercado, todo ello, puede ser comprendido como un intento por maximizar la riqueza social. Seguramente el AED podrá ofrecer tesis que satisfagan plausiblemente los requisitos de las explicaciones internas y tesis que se adecúen al modelo de explicación externa. Lo único que intenté criticar en este trabajo es la pretensión de brindar una explicación interna del Derecho de daños con los instrumentos predictivos de la explicación externa.

\section{BIBLIOGRAFÍA}

BAyón, J. C., 2002: «Justicia y eficiencia», en E. Díaz y J. L. Colomer (eds.), Estado, justicia y derechos, Madrid, Alianza.

BRENNER, R., 1980: «Economics-An imperialist Science?», en Journal of Legal Studies, 9(1): 179188.

BRown, J. P., 1973: «Toward an Economic Theory of Liability», en The Journal of Legal Studies, 2(2): 323-349.

Calabresi, G., 1970: The Costs of Accidents. A Legal and Economic Analysis, New Haven and London, Yale University Press.

- 1975: «Concerning Cause and the Law of Torts: An Essay for Harry Kalven, Jr.», en University of Chicago Law Review, 43(1): 69-108.

- 1980: «An Exchange. About Law and Economics: a Letter to Ronald Dworkin», en Hofstra Law Review, 8(3): 553-562.

Calabresi, G., y Melamed, A. D., 1972: «Property Rules, Liability Rules, and Inalienability: One View of the Cathedral», en Harvard Law Review, 85(6): 1089-1128.

Cane, P., 2006: Atiyab's Accidents, Compensation and the Law, 7. ${ }^{a}$ ed., Cambridge, Cambridge University Press.

CoAse, R., 1960: «The Problem of Social Cost», en The Journal of Law and Economics, 3: 1-44.

análisis siempre será incompleto. Por supuesto, rescata el valor de los estudios que intentan predecir los efectos de las normas jurídicas. Vid. COOTER, 1982, p. 1266.

${ }^{90}$ POSNeR, 1979b, p. 297. 
Coleman, J. L., 1992: Risks and Wrongs, Oxford, Oxford University Press.

- 2001: The practice of principle, Oxford, Oxford University Press.

Coloma, G., 2001: Análisis Económico del Derecho Privado y Regulatorio, Buenos Aires, Ciudad Argentina.

CoOTeR, R., 1982: «Law and the Imperialism of Economics: An Introduction to the Economic Analysis of Law and a Review of the Major Books», en UCLA Law Review, 29(6): 12601269.

- 1987: «Torts as the Union of Liberty and Efficiency: An Essay on Causation», en ChicagoKent Law Review, 63(3): 523-551.

DurkHeim, E., [1895]: Las reglas del método sociológico, México, Fondo de Cultura Económica, 1986.

Dworkin, R., 1980: «Is Wealth a Value?», en The Journal of Legal Studies, 9(2): 191-226.

— 1980b: «Why Efficiency? A response to Professors Calabresi and Posner», en Hofstra Law Review, 8(3): 563-590.

FeInberg, J., 1984: Harm to Others. The Moral Limits of the Criminal Law, Oxford, Oxford University Press.

FISS, O. M., 1986: «The Death of the Law?», en Cornell Law Review, 72(1): 1-16.

Fried, C., 1978: Right and Wrong, Cambridge-Mass.-London, Harvard University Press.

Gilles, S. G., 1992: «Rule-Based Negligence and the Regulation of Activity Levels», en The Journal of Legal Studies, 21(2): 319-363.

Hart, H. L. A., y Honoré, T., 1985: Causation in the Law, 2. ${ }^{a}$ ed., Oxford, Oxford University Press.

Hierro, L., 1993: «Contra el imperio de la riqueza (Dworkin vs. Posner)», en Ronald Dworkin. Estudios en su homenaje. Revista de Ciencias Sociales (Universidad de Valparaíso), 38: 383 411.

- 1994: «La pobreza como injusticia (Dworkin vs. Calabresi)», en Doxa, 15-16: 945-969.

- 1998: «Justicia, igualdad y eficiencia», en Isonomía, 9: 129-171.

JAKOBS, G., 2002: La imputación objetiva en el Derecho penal, trad. M. CANCIO MELIÁ, Buenos Aires, Ad-Hoc.

Kraus, J. S., 2007: «Transparency and Determinacy in Common Law Adjudication: A Philosophical Defense of Explanatory Economic Analysis», en Virginia Law Review, 93(2): 287359.

LANDEs, W., y Posner, R. A., 1983: «Causation in Tort Law: An Economic Approach», en Journal of Legal Studies, 12(1): 109-134.

- 1987: The Economic Structure of Tort Law, Cambridge, Mass., y London, England, Harvard University Press.

Ogus, A., 2004: «What Legal Scholars Can Learn from Law and Economics», en Chicago-Kent Law Review, 79(2): 383-401.

Pigou, A. C., 1932: The Economics of Welfare, London, Macmillan.

Polinksy, M. A., y Shavell, S., 1998: «Punitive Damages: An Economic Analysis», en Harvard Law Review, 111(4): 869-962.

Posner, R. A., 1972: «A Theory of Negligence», en The Journal of Legal Studies, 1(1): 29-96.

- 1979: «Utilitarianism Economics, and Legal Theory», en Journal of Legal Studies, 8(1): 103 140.

- 1979b: «Some Uses and Abuses of Economics in Law», en The University of Chicago Law Review, 46(2): 281-306. 
- 1990: The Problems of Jurisprudence, Cambridge, Mass., Harvard University Press.

- 1996: Law and Legal Theory in England and America, Oxford, Clarendon Press.

- 1998: Economic Analysis of Law, Aspen Law and Business.

RAZ, J., 1996: «On the Nature of Law», en Archiv für Rechts- und Sozialphilosopbie, 82: 1-25.

RosenKRANTZ, C. F., 2005: «La justicia correctiva y la responsabilidad extracontractual: donde la Filosofía del Derecho y la Economía se encuentran», en C. F. RosENKRANTZ (comp.): La responsabilidad extracontractual, Barcelona, Gedisa.

SHAVELL, S., 1980: «An Analysis of Causation and the Scope of Liability in the Law of Torts», en Journal of Legal Studies, en 9(3): 463-516.

- 1987: Economic Analysis of Accident Law, Cambridge, Mass., London, Harvard University Press.

— 2007: «Liability for Accidents», en M. POLINSKY y S. SHAvell, Handbook of Law and Economics. Vol. 1, Amsterdam, Elsevier-North Holland.

Sunstein, C. R.; Schkade, D. A., y Kahneman, D., 2002: «Do People Want Optimal Deterrence?», en C. SunsteIN et al., Punitive Damages. How Juries Decide, Chicago and London, University of Chicago Press: 132-141.

WeInRIB, E., 1989: «Understanding Tort Law», en Valparaiso University Law Review, 23(3): 485-526.

- 1995: The Idea of Private Law. Cambridge, Mass., Harvard University Press.

Wright, R. W., 1985: «Actual Causation vs. Probabilistic Linkage: The Bane of Economic Analysis», en The Journal of Legal Studies, 14(2): 435-456.

— 2003: «Hand, Posner, and the Myth of the "Hand Formula"», en Theoretical Inquiries in Law, 4: 1-132. 